\title{
CD137 (4-1BB) stimulation leads to metabolic and functional reprogramming of human monocytes/macrophages enhancing their tumoricidal activity
}

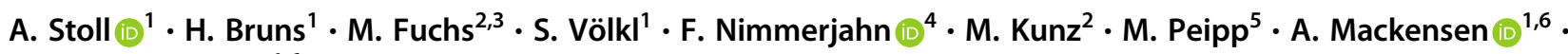 \\ D. Mougiakakos (iD ${ }^{1,6}$
}

Received: 15 January 2021 / Revised: 29 April 2021 / Accepted: 5 May 2021 / Published online: 21 May 2021

(c) The Author(s) 2021. This article is published with open access

\begin{abstract}
Immunotherapies have heralded a new era in the cancer treatment. In addition to checkpoint inhibitors, agonistic antibodies against co-stimulatory immune receptors hold the potential to invoke efficient antitumor immunity. Targeting CD137 has gained momentum based on its ability to drive NK- and T-cell-based responses. CD137-engaging mAbs have already entered clinical trials for different types of tumors showing promising results. Despite the efforts to translate CD137mediated immunotherapy into clinical practice, little remains known regarding the role of CD137 in human monocytes/ macrophages.

We found CD137 being expressed on monocytes of healthy controls and at even higher levels in patients with multiple myeloma or CLL. CD137 ${ }^{\mathrm{HI}(\mathrm{GH})}$ monocytes displayed a distinct phenotypic, transcriptomic, and metabolic profile. They possessed an increased phagocytic capacity enabling superior antibody-dependent phagocytosis (ADPC) of multiple myeloma and lymphoma cells that were treated with anti-CD38 or anti-CD20 mAbs. Triggering CD137 promoted both metabolic and tumoricidal activity in an extracellular signal-regulated kinase (ERK)-dependent fashion. In addition, we observed a phenotypic, transcriptomic, and functional skewing towards a M1-like phenotype.

Overall, we introduce CD137 as a positive immune checkpoint on human monocytes/macrophages, which can have therapeutic implications especially in view of synergistic effects when combining CD137 agonists with tumor-targeting antibodies.
\end{abstract}

Supplementary information The online version contains supplementary material available at https://doi.org/10.1038/s41375021-01287-1.

D. Mougiakakos

dimitrios.mougiakakos@uk-erlangen.de

1 Department of Medicine 5 for Hematology and Oncology, Friedrich-Alexander-Universität Erlangen-Nürnberg, Erlangen, Germany

2 Chair of Medical Informatics, Friedrich-Alexander University (FAU) of Erlangen-Nürnberg, Erlangen, Germany

3 Functional Genomics and Systems Biology Group, Department of Bioinformatics, University of Würzburg, Würzburg, Germany

4 Division of Genetics, Department of Biology, FriedrichAlexander-Universität Erlangen-Nürnberg, Erlangen, Germany

5 Division of Stem Cell Transplantation and Immunotherapy, Department of Medicine II, Christian-Albrechts-University Kiel, Kiel, Germany

6 Deutsches Zentrum für Immuntherapie (DZI), Erlangen, Germany

\section{Introduction}

To date, tumor immunosurveillance and tumor immunoediting are well-established concepts. Moreover, immunotherapy represents one the most appealing anti-cancer approaches [1]. Two key strategies are currently intensely pursued: adoptive transfer of genetically engineered immune cells (e.g., chimeric antigen receptor/CAR T-cells) or application of agents that activate the patients' immune system (by e.g., blockade of negative immune checkpoints) and thereby re-invigorate intrinsic antitumor immunity. Immune checkpoint receptors are membrane molecules on immune cells, which upon binding to their cognate ligand on tumors or tumor-associated cells can negatively (i.e., inhibitory receptors) or positively (i.e., stimulatory receptors) impact the immune cells' function. Examples for inhibitory receptors that are successfully targeted in the clinical practice include programmed cell death protein 1 (PD-1) and cytotoxic T-lymphocyte-associated protein 4 [2]. 
The cell surface glycoprotein CD137, which is also known as 4-1BB, belongs to the group of co-stimulatory immune receptors and is a member of the TNF receptor superfamily. It is preferentially found on activated T-cells and regulatory $\mathrm{T}$-cells $\left(\mathrm{T}_{\text {Regs }}\right)$ but also innate immune cells, such as natural killer (NK-) cells, neutrophils, and monocytes can express CD137 [3-5]. Antigen-presenting cells, such as dendritic cells predominantly express, especially in response to stimulatory trigger, its natural ligand CD137-L. The CD137/CD137-L interaction leads to the recruitment of TNF receptor-associated factors $1 / 2$ and the downstream activation of the nuclear factor kappa B transcriptional pathway [6]. In T-cells, CD137 crosslinking delivers a potent co-stimulatory signal as it promotes T-cell proliferation and formation of memory cells, enhances survival, and increases the production of interferon- $\gamma$ (IFN- $\gamma$ ) and interleukin-2 (IL-2) [7]. Moreover, CD137 signaling has been shown to hold the potential to reprogram tolerogenic $\mathrm{T}_{\text {Regs }}$ into effector $\mathrm{T}$-cells with antitumor activity [4]. In fact, incorporating the intracellular signaling domain of CD137 fosters clinical activity of CAR T-cells further highlighting its importance for antitumor immunity [8]. Likewise, NK cells respond to CD137 stimulation with increased proliferation, production of IFN- $\gamma$, and the ability to perform antibody-dependent cell-mediated cytotoxicity (ADCC) against malignant cells [9].

Consistent with its co-stimulatory function, agonistic monoclonal antibodies (mAbs) against CD137 have elicited effective antitumor immune responses in preclinical models that have been mainly attributed to the activation of T-cells and/or NK cells [10-12]. Actually, CD137-engaging mAbs, such as Urelumab or Utomilumab have already entered clinical trials for different types of tumors (e.g., melanoma or lung cancer) demonstrating their efficacy $[13,14]$. However, the role of CD137 signaling in human monocytes/macrophages remains relatively unexplored. In fact, monocyte/ macrophage lineage cells accumulate in numerous malignant entities. Tumor-associated monocytes/macrophages (TAMs) regularly display a pro-tumoral M2 phenotype. They do not only provide nurturing signals by e.g., stimulating angiogenesis but also inhibit antitumor immune responses [15]. At the same time, several reports highlight the potential antitumor function of monocytes/macrophages as mediators of antibody-based therapies against cancer, such as anti-CD20 or anti-Her2 mAbs or potentiators of adaptive immune responses [16, 17]. Importantly, intrinsic tumoricidal capacity is retained in the M2-like cells and can be reactivated by disrupting M2-promoting signals leading to the formation of a rather immunoreactive M1 phenotype [18]. Given their central role in tumor development and tumor progression as well as their functional plasticity, monocytes/macrophages represent ideal candidates for therapeutic interventions. However, to fully unleash their tumoricidal capacity, it can be necessary to previously overcome certain immunosuppressive hurdles. Blocking the negative immune checkpoint CD47 or triggering the positive immune checkpoint CD40 has led to an efficient macrophage-mediated tumor regression $[19,20]$.

In this study, we hypothesized that CD137 might act as a co-stimulatory receptor on human monocytes/macrophages that could hold the potential to enhance their tumor-directed activities. We found CD137 being expressed on circulating monocytes of healthy controls and at even higher levels on cancer patient-derived cells. In fact, CD137 ${ }^{\mathrm{HI}(\mathrm{GH})}$ monocytes displayed a distinct phenotypic, transcriptomic, and metabolic profile. They possessed an increased phagocytic capacity enabling a superior antibody-dependent phagocytosis of multiple myeloma (MM) and lymphoma cells that were treated with anti-CD38 or anti-CD20 mAbs, respectively. Agonistic triggering of CD137 on myeloid cells promoted both metabolic and tumoricidal activity in an extracellular signal-regulated kinase (ERK)-dependent fashion. In addition, we observed a phenotypic, transcriptomic, and functional skewing towards a M1-like phenotype. Taken together, we identified CD137 as a novel positive immune checkpoint on human monocytes/macrophages, which can have therapeutic implications especially in view of an added therapeutic value when combining CD137 agonists with tumor-targeting mAbs.

\section{Methods}

\section{Patient material}

Peripheral blood mononuclear cells and bone marrow samples from MM patients and healthy donors were collected upon approval by the local ethics committee (Ref. number 3555, 36_12 B, 219_14B, 200_12B) and participants' written informed consent in accordance with the Declaration of Helsinki.

\section{Cell lines, antibodies, and primers}

Cell lines, antibodies, and primers used are listed in Supplementary Tables 1-3.

\section{CD137 stimulation}

Anti-human CD137 mAbs (Clone 4B4-1, Biolegend) or mouse $\operatorname{IgG} 1, \kappa$ isotype control (Biolegend) were diluted to $10 \mu \mathrm{g} / \mathrm{ml}$ in DPBS (ThermoFischer Scientific) and coated to 48-well plate (Corning) at $4{ }^{\circ} \mathrm{C}$ overnight. Afterwards, coating solution was removed and MACS- purified monocytes were cultured at $0.5 \times 10^{6}$ /well for 4 days unless otherwise specified. For repolarization experiments, M2 
macrophages were cultured instead of monocytes under the same conditions for 3 days.

For the inhibition of ERK1/2 signaling upon CD137 triggering, selective ERK1/2 inhibitors Ravoxertinib or SCH772984 (Selleckchem) were added to culture medium at different concentrations directly after seeding the monocytes.

\section{Macrophage generation}

Monocytes were cultured for 6 days in presence of $50 \mathrm{ng} / \mathrm{ml}$ GM-CSF (Berlex, Leukine) or $50 \mathrm{ng} / \mathrm{ml}$ M-CSF (R\&D Systems) to generate M1- and M2 macrophages, respectively.

\section{Phagocytosis assays}

Target cells were labeled with $0.5 \mu \mathrm{M}$ CFSE (Invitrogen) in DPBS/ $0.1 \%$ FCS and opsonized with different concentrations of therapeutic antibodies Daratumumab (Janssen, Darzalex $^{\circledR}$ ) or Rituximab (Roche, MabThera ${ }^{\circledR}$ ). Monocytes were co-cultured with target cells at different effector to target (E:T) ratios in sterile FACS tubes for $4 \mathrm{~h}$. Subsequently, surface staining of cells was performed for FACS analysis.

Phagocytosis of pathogens by healthy donor- or patientderived monocytes was assessed using pHrodo $^{\mathrm{TM}}$ Green E. coli (ThermoFisher Scientific) and analyzed by FACS.

\section{Tumor cell clearance}

Monocytes were co-cultured with CPD-labeled (ThermoFisher Scientific) target cells $(\mathrm{E}: \mathrm{T}=5: 1)$ in the presence or absence of Daratumumab $(10 \mu \mathrm{g} / \mathrm{ml})$ or Rituximab $(10 \mu \mathrm{g} / \mathrm{ml})$ for $24 \mathrm{~h}$. Monocytes were counterstained with anti-CD11b-FITC. Absolute numbers of surviving target cells were determined by FACS analysis of $\mathrm{CD} 11 \mathrm{~b}^{-} / \mathrm{CPD}^{+}$ cells via 123 count eBeads (ThermoFisher Scientific).

\section{Extracellular flux analysis}

One day prior to measurements, Seahorse XFe96 culture plates (Agilent Technologies) were coated with Corning TM Cell-Tak Cell and Tissue Adhesive (BD Biosciences). An XFe96 cartridge (Agilent Technologies) was loaded with XF Calibrant solution (Agilent Technologies) and incubated overnight in a $\mathrm{CO}_{2}$-free atmosphere. Next, cells were washed in assay-specific medium according to the manufacturer's recommendations and viability determined using a Muse Cell Analyzer (Merck Millipore). Viable cells were seeded at a density of $2 \times 10^{5}$ monocytes in $175 \mu \mathrm{L}$ per well. The ports of the cartridges were loaded with $25 \mu \mathrm{L}$ each of $80 \mathrm{mM}$ glucose, $9 \mu \mathrm{M}$ oligomycin, and $1 \mathrm{M} 2 \mathrm{DG}$ for the glycolysis stress test and $20 \mu \mathrm{L}$ of $10 \mu \mathrm{M}$ oligomycin, $22 \mu \mathrm{L}$ of $15 \mu \mathrm{M}$ FCCP, and $25 \mu \mathrm{L}$ of $30 \mu \mathrm{M}$ antimycin $\mathrm{A} /$ rotenone for the mitochondrial stress test. After sensor calibration, assays were run as detailed in the manufacturer's manual by recording extracellular acidification rate (ECAR) and oxygen consumption rate (OCR). Metabolic parameters were obtained from the XF Wave software (Agilent/Seahorse Biosciences) and calculated using Microsoft Excel.

\section{Statistics}

Statistics were calculated with Graphpad Prism Version 9 (La Jolla, California, USA). Comparisons between groups were performed using the appropriate statistical methods depending on Gaussian distribution and number of groups and variables, i.e., one-way ANOVA with Tukey's post hoc test, two-way ANOVA with Bonferroni post hoc test, unpaired and paired two-tailed $t$-test, and Mann-Whitney test.

\section{Results}

\section{CD137 expression level identifies circulating monocytes with a distinct phenotypic and transcriptomic profile in vivo}

First, we sought out to assess whether CD137 is expressed on the main subsets of circulating healthy donor-derived monocytes. Subset classification by flow cytometry (FACS) was based on the CD14 and CD16 expression and resulted in three different populations namely, classical $\left(\mathrm{CD} 14^{++}\right.$, $\left.\mathrm{CD} 16^{\text {neg }}\right)$, intermediate $\left(\mathrm{CD} 14^{+}, \mathrm{CD} 16^{+}\right)$, and non-classical $\left(\mathrm{CD} 14^{\text {neg }}, \mathrm{CD} 16^{++}\right)$monocytes (Fig. 1Ai). CD137 was found expressed on all the tested monocytic subtypes (Fig. 1Aii). For the subsequent comparative analyses, we grouped monocytes in accordance to their CD137 expression level into $\mathrm{CD} 137^{\mathrm{HI}(\mathrm{GH})}$ and $\mathrm{CD} 137^{\mathrm{LO}(\mathrm{W})}$ cells (Fig. 1Aiii). In fact, CD137 ${ }^{\mathrm{HI}}$ cells displayed a significantly higher CD14 expression and a tendency towards lower levels of the Fc $\gamma$ receptor CD16 (Fig. 1B). Consequently, we found classical monocytes being overrepresented within the $\mathrm{CD} 137^{\mathrm{HI}}$ and non-classical within the $\mathrm{CD} 137^{\mathrm{LO}}$ compartment, respectively (Fig. 1C).

Next, we assessed surface molecules on $\mathrm{CD} 137^{\mathrm{HI}}$ and $\mathrm{CD} 137^{\mathrm{LO}}$ monocytes that have been reported as differentially expressed on classical versus non-classical subsets including CD11b (classical > non-classical), CD32 (classi$\mathrm{cal}=$ non-classical), CD64 (classical $>$ non-classical), CD86 (classical $<$ non-classical), CD120b (classical $<$ non-classical), as well as HLA-DR (classical < non-classical) [21, 22]. In line with the previously reported characteristics of classical and non-classical monocytes, we measured higher levels of $\mathrm{CD} 11 \mathrm{~b}$ and $\mathrm{CD} 64$ on $\mathrm{CD} 137^{\mathrm{HI}}$ cells. Conversely, expression was also superior for CD32, CD86, and CD120b 

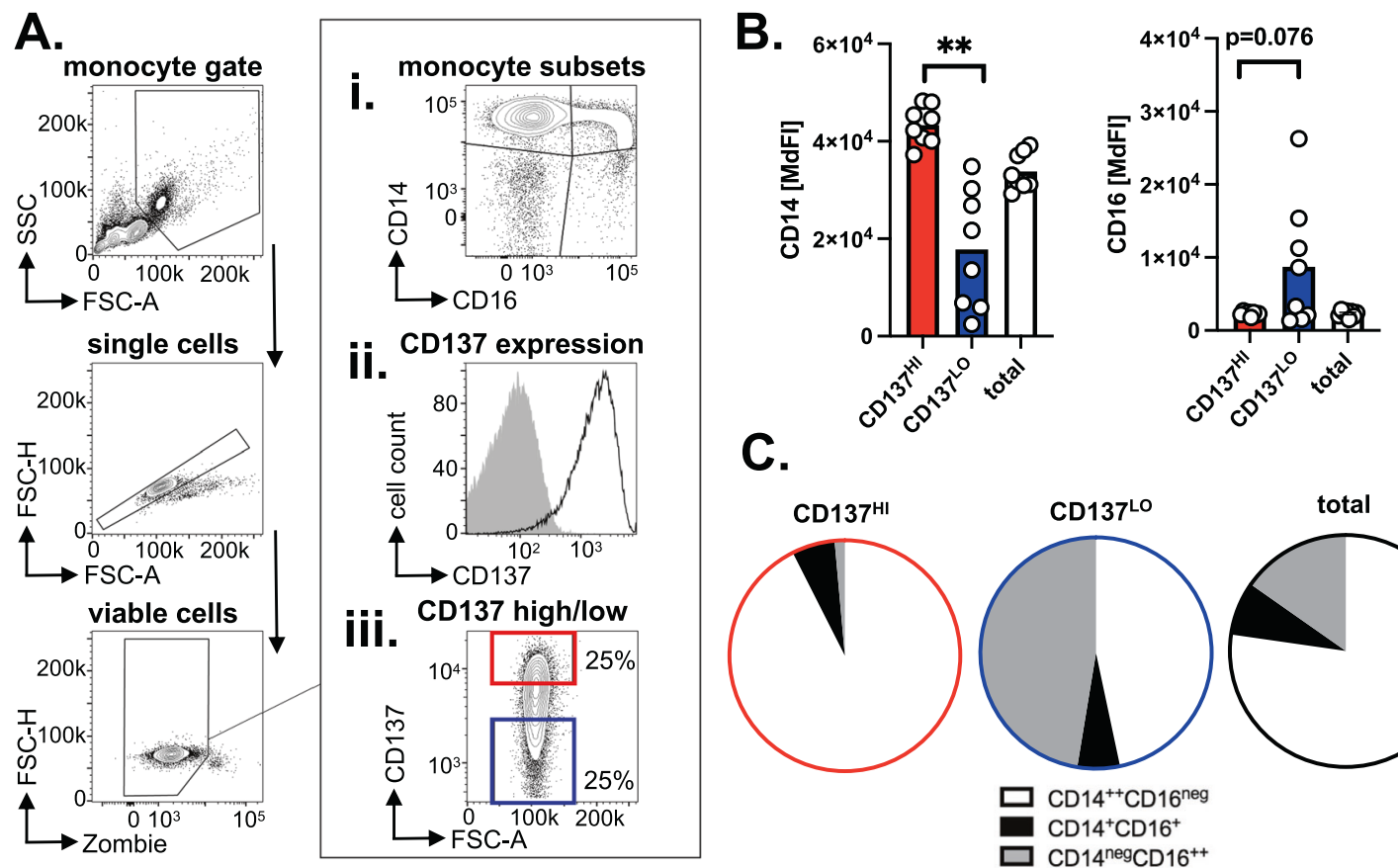

C.

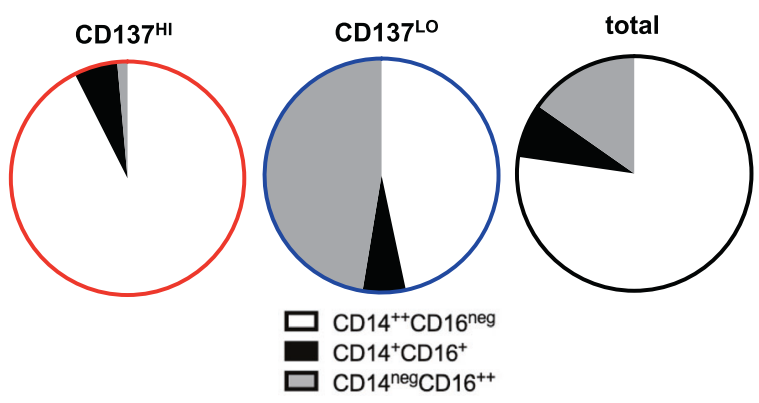

D.
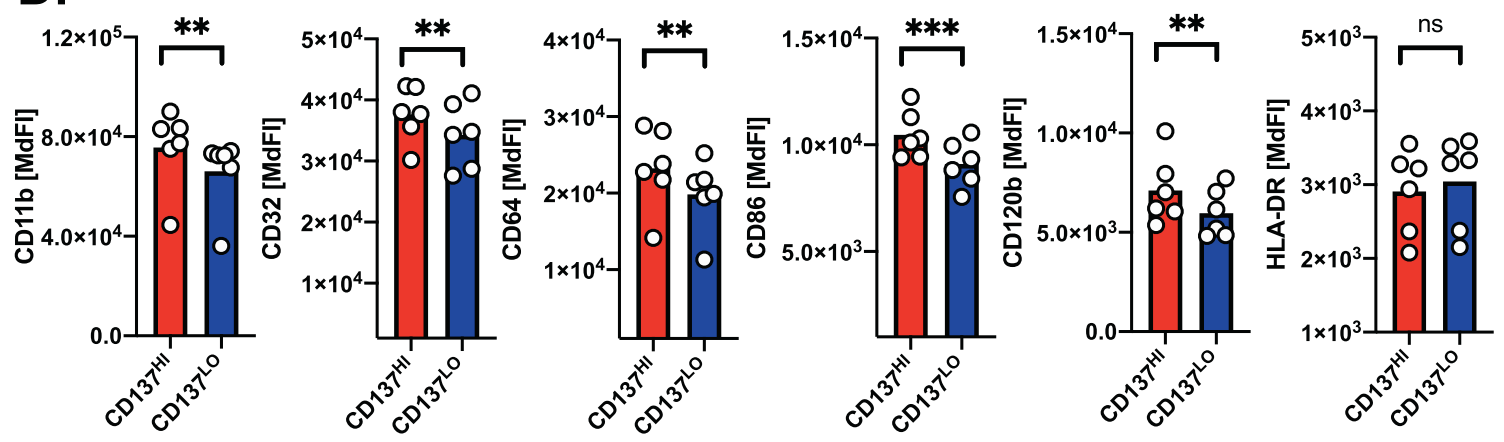

E.

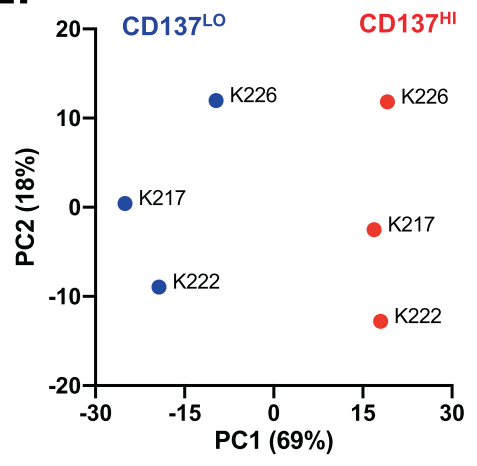

F.

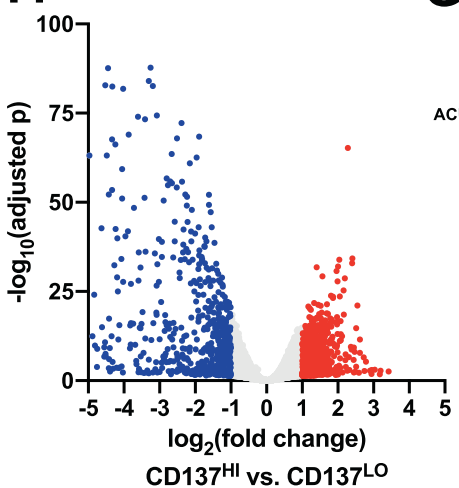

G.

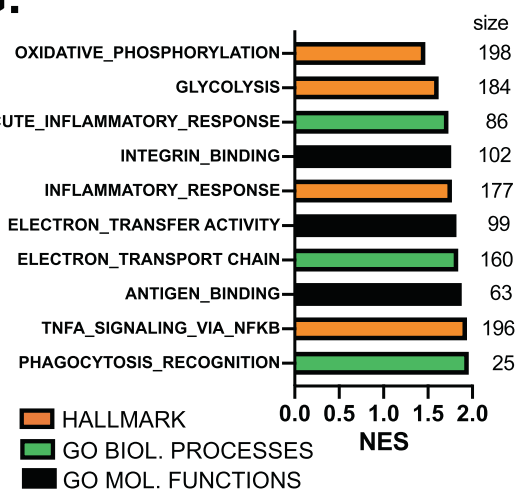

pointing towards an, if at all, only partial overlap between $\mathrm{CD} 137^{\mathrm{HI}}$ and classical monocytes (Fig. 1D).

To confirm distinct features in $\mathrm{CD} 137^{\mathrm{HI}}$ and $\mathrm{CD} 137^{\mathrm{LO}}$ monocytes, we FACS-sorted both populations followed by a RNA-seq analysis (GSE171108). The principal component analysis (PCA) together with the gene expression profiling suggest a separation between both populations
(Fig. 1E, F). Furthermore, our gene set enrichment analyses (GSEA) revealed that $\mathrm{CD} 137^{\mathrm{HI}}$ cells are significantly enriched for genes that are amongst others involved in metabolism, inflammation, and phagocytosis (Fig. 1G). When comparing our transcriptome profiles with a publicly available RNA-seq dataset (GSE107011), the notion that $\mathrm{CD} 137^{\mathrm{HI}}$ and $\mathrm{CD} 137^{\mathrm{LO}}$ overlap with classical and 
Fig. $1 \mathrm{CD137}{ }^{\mathrm{HI}(\mathrm{GH})}$ monocytes display and distinct phenotypic and transcriptomic profile. A Peripheral blood-derived monocytes were analyzed by flow cytometry (FACS) in terms of CD14 and CD16 expression patterns, CD137 expression, and CD137 expression levels as shown in this representative gating strategy. B CD14 and CD16 expression was quantified in $\mathrm{CD} 137^{\mathrm{HI}}, \mathrm{CD} 137^{\mathrm{LO}(\mathrm{W})}$, and total monocytes $(n=8)$ by FACS based on the median fluorescence index (MdFI). C The proportion of $\mathrm{CD} 14^{++} \mathrm{CD} 16^{\text {neg }} /$ classical, $\mathrm{CD} 14^{+} \mathrm{CD} 16^{+} /$intermediate, and $\mathrm{CD} 14^{\text {neg }} \mathrm{CD} 16^{++} /$non-classical monocytes among $\mathrm{CD} 137^{\mathrm{HI}}, \mathrm{CD} 137^{\mathrm{LO}}$, and total monocytes $(n=8)$ was determined by FACS and is shown as a pie chart. D Expression of CD11b, CD32, CD64, CD86, CD120b, and HLA-DR was quantified on CD137 ${ }^{\mathrm{HI}}$ and $\mathrm{CD} 137^{\mathrm{LO}}$ monocytes $(n=6)$ by FACS. E CD137 ${ }^{\mathrm{HI}}$ and $\mathrm{CD} 137^{\mathrm{LO}}$ monocytes $(n=3)$ were purified by FACS-sorting followed by RNA sequencing. The principal component (PC) analysis of differentially expressed genes separates along PC1 according to CD137 expression level. F Volcano plot of differentially expressed genes showing genes (each dot represents one gene) with an at least twofold upregulation (red) or downregulation (blue) in $\mathrm{CD} 137^{\mathrm{HI}}$ monocytes, as well as a high number of significantly differentially expressed genes $(q<0.1: 5513$ genes). G Gene set enrichment analysis of differential gene expression between $\mathrm{CD} 137^{\mathrm{HI}}$ and $\mathrm{CD} 137^{\mathrm{LO}}$ monocytes. Graph depicts significantly enriched pathways found in MSigDB hallmark (orange) and gene ontology (green and black) sets. Size of gene set is annotated to the right. Bar length corresponds to normalized enrichment score (NES). $* p<0.05 ; * * p<0.01 ; * * * p<0.001$.

non-classical monocytes respectively only partially is further corroborated (Supplementary Fig. 1) [23].

\section{CD137 ${ }^{\mathrm{HI}}$ monocytes possess a superior metabolic armamentarium and a proglycolytic phenotype}

Metabolic competence is a prerequisite for monocytes/ macrophages to efficiently carry out their antitumoral functions [24]. Our transcriptome analysis revealed an enhanced expression of molecules involved in both glycolysis and oxidative phosphorylation for the $\mathrm{CD} 137^{\mathrm{HI}}$ subset (Fig. 1G). This would fit the observation that CD137 signaling activates glycolysis and fatty acid metabolism in $\mathrm{CD}^{+}$T-cells [25]. In line with our mRNA profiles, we found higher levels of the glucose transporter 1 (GLUT1) and the glycolytic pacemaker enzyme hexokinase 2 (HK2) in the $\mathrm{CD} 137^{\mathrm{HI}}$ cells. Uptake of the fluorescently labeled glucose analog 6-NBDG was similar in both CD137 groups (Fig. 2A). In addition, the fatty acid transporter CD36, uptake of BODIPY-linked fatty acids, and carnitine O-palmitoyltransferase 1 (CPT1a) the key molecule shuttling long-chain fatty acids into the mitochondrion to be oxidized were all elevated in the $\mathrm{CD} 137^{\mathrm{HI}}$ subset (Fig. 2B).

Next, we concentrated on the mitochondria as one of the cells' central hubs that integrates bioenergetics and immune responses. Assessment of mitochondrial mass and mitochondrial DNA revealed an increased mitochondrial biogenesis in $\mathrm{CD} 137^{\mathrm{HI}}$ cells (Fig. 2C). The mitochondrial membrane potential $(\Delta \psi \mathrm{m})$ has been shown to act as a reliable marker for mitochondrial activity that powers ATP energy formation [26]. $\mathrm{CD} 137^{\mathrm{HI}}$ cells displayed a higher $\Delta \psi \mathrm{m}$, which was accompanied by increased mitochondrial reactive oxygen species (MitoSOX) (Fig. 2D, E) and which can be observed during M1 polarization [27]. Mitochondria represent highly dynamic organelles that continuously shift between fusion and fission in response to intrinsic and extrinsic stimuli. Mitofusin-2 (MFN-2) plays a key role for fusion and is also involved in promoting $\Delta \psi \mathrm{m}$, mitochondrial ROS production as well as proinflammatory activation, cytokine production, and phagocytosis [28]. In fact, MFN-2 was significantly higher in the $\mathrm{CD} 137^{\mathrm{HI}}$ population (Fig. $2 \mathrm{~F}$ ).

In order to complete our metabolic mapping, we performed metabolic flux analyses of FACS-sorted CD137 ${ }^{\mathrm{HI}}$ and $\mathrm{CD} 137^{\mathrm{LO}}$ monocytes. ECAR is indicative for aerobic glycolysis and OCR for oxidative phosphorylation (OXPHOS) (Fig. 2G). Basal glycolysis was significantly elevated in $\mathrm{CD} 137^{\mathrm{HI}}$ cells and we observed a strong trend towards a reduced respiratory rate (Fig. $2 \mathrm{H})$. Consequently, the OCR/ECAR ratio in $\mathrm{CD} 137^{\mathrm{HI}}$ cells was skewed towards ECAR resulting in an overall proglycolytic phenotype (Fig. 2I), which is similarly described for monocytes and macrophages following proinflammatory activation [29]. When evaluating the cells' bioenergetic reserve capacities that co-determine their ability to adapt to cellular stress, we noticed a superior glycolytic reserve in $\mathrm{CD} 137^{\mathrm{HI}}$ cells and a relatively comparable spare respiratory capacity (Fig. 2J). In accordance to the higher $\Delta \psi \mathrm{m}$, we observed a reduced proton leak and a trend towards better coupling efficiency in CD137 ${ }^{\mathrm{HI}}$ cells (Fig. 2K).

\section{CD137 ${ }^{\mathrm{HI}}$ monocytes display an enhanced phagocytic activity}

The RNA-seq analysis of $\mathrm{CD} 137^{\mathrm{HI}}$ versus $\mathrm{CD} 137^{\mathrm{LO}}$ monocytes revealed the increased expression of a number of molecules involved in phagocytosis as accordingly mapped in the KEGG "Phagosome" pathway (hsa04145) (Fig. 3A). Phagocytosis plays an important role in the host immune defense as well as in antitumor immunity. In order to validate our gene expression data, we cultured $\mathrm{CD} 137^{\mathrm{HI} / \mathrm{LO}}$ monocytes from healthy donors but also patients with chronic lymphocytic leukemia (CLL) or MM in presence of conjugated E. coli bioparticles. In this flow cytometry-based assay a positive signal occurs upon particle internalization and acidification, which are activities indicative for phagocytic actions. In line with the RNA-seq data, we found a significantly higher fraction of positive cells among the $\mathrm{CD} 137^{\mathrm{HI}}$ population (Fig. 3B).

Tumor-targeting antibodies are considered to be one of the most successful strategies in cancer therapy. The antigens CD20 and CD38 are expressed on most B-cell-derived malignancies and $\mathrm{MM}$ cases respectively, which has been translated into efficient mAb-based therapies [30, 31]. 
A.

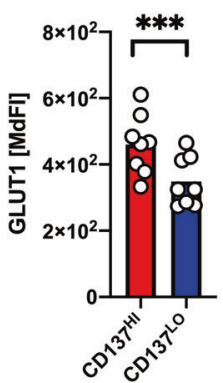

C.

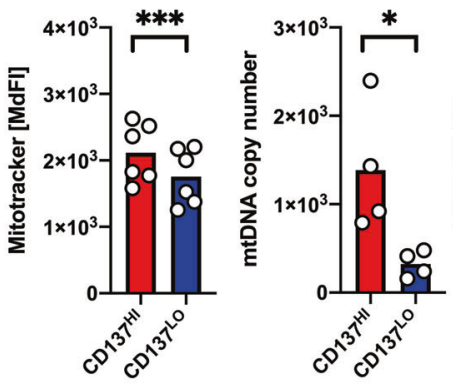

G.

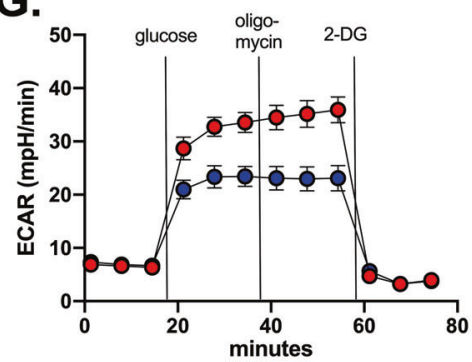

I.

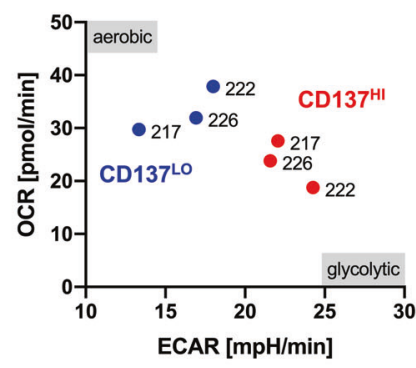

D.
B.
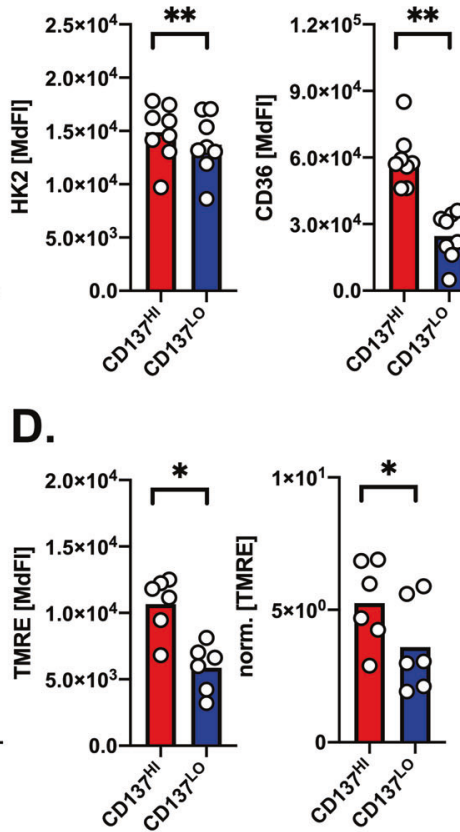

E.

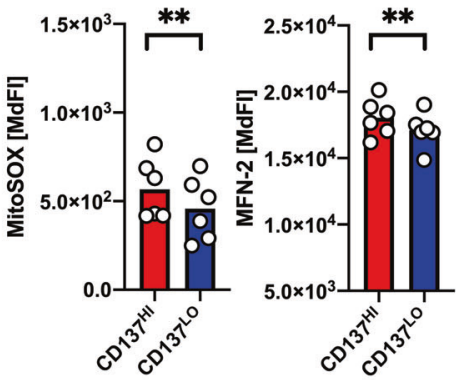

H.

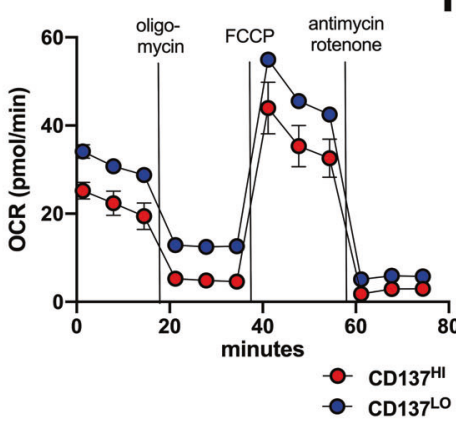

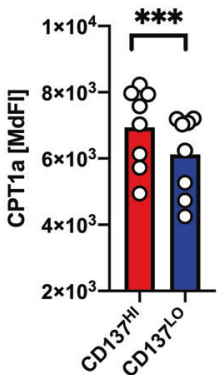

F

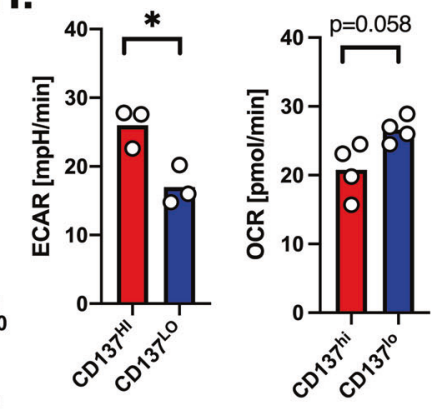

J.

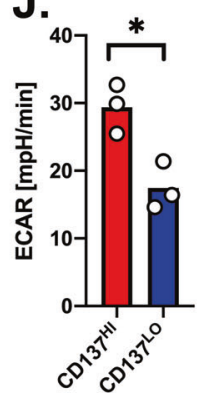

K.

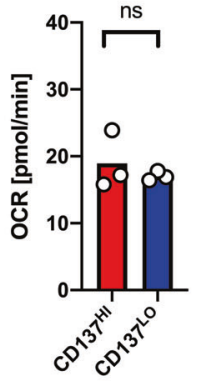

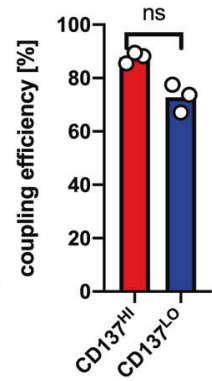

Myeloid cells are abundantly present in the microenvironment of both entities $[32,33]$. Therefore, we sought out to evaluate the ability of $\mathrm{CD} 137^{\mathrm{HI} / \mathrm{LO}}$ monocytes to clear malignant cell in presence of tumor-targeting mAbs. First, we evaluated several fluorescently labeled $\mathrm{CD} 20^{+} \mathrm{B}$-cell malignancy-derived cell lines (Burkitt lymphoma: BL-41, BJAB, and Raji, CLL: MEC-1) applying the clinically approved anti-CD20 mAb Rituximab. As anticipated, antibody-dependent cellular phagocytosis (ADCP) was superior in $\mathrm{CD} 137^{\mathrm{HI}}$ cells. Moreover, we made equivalent observations, when using $\mathrm{CD} 38^{+} \mathrm{MM}$-derived cell lines (OPM-2, MM.1 S, RPMI-8826, U-266) that were treated with the anti-CD38 mAb Daratumumab (Fig. 3C, Supplementary Fig. 2).

\section{CD137 stimulation promotes metabolic and tumoricidal activity of monocytes}

TAMs are components of the tumor microenvironment and often associated with a dismal prognosis. However, 
Fig. $2{\mathrm{CD} 137^{\mathrm{HI}}}$ monocytes possess a superior metabolic fitness and a proglycolytic phenotype. A Expression of glucose transporter GLUT1 $(n=8)$, uptake of glucose analog 6-NBDG $(n=6)$, and glycolytic pacemaker enzyme hexokinase 2 (HK2) level $(n=8)$ were determined by FACS in $\mathrm{CD} 137^{\mathrm{HI}}$ and $\mathrm{CD} 137^{\mathrm{LO}}$ monocytes. B Expression of fatty acid transporter $\operatorname{CD} 36(n=8)$, uptake of fatty acids linked to the fluorophore BODIPYTM FL C16 staining $(n=6)$, and level of the key enzyme shuttling fatty acids into the mitochondria carnitine palmitoyltransferase I (CPT1) $(n=8)$ were determined by FACS in $\mathrm{CD} 137^{\mathrm{HI}}$ and $\mathrm{CD} 137^{\mathrm{LO}}$ monocytes. C The mitochondrial mass in $\mathrm{CD} 137^{\mathrm{HI}}$ and $\mathrm{CD} 137^{\mathrm{LO}}$ monocytes was determined by FACS using the mitochondrial dye MitoTracker $(n=6)$ or by measuring the relative (to nuclear DNA) mitochondrial DNA (mtDNA) copy number $(n=4)$. D Mitochondrial membrane potential was assessed in $\mathrm{CD} 137^{\mathrm{HI}}$ and $\mathrm{CD} 137^{\mathrm{LO}}$ monocytes $(n=6)$ by FACS using the potentiometric dye tetramethylrhodamine ethyl ester (TMRE). The right panel shows the TMRE values normalized for cell size. $\mathbf{E}$ Mitochondrial-specific production of reactive oxygen species (MitoSOX) ( $n=5)$ and $\mathbf{F}$ expression of mitofusin-2 (MFN-2) $(n=6)$, which regulates mitochondrial fusion were determined by FACS in $\mathrm{CD} 137^{\mathrm{HI}}$ and $\mathrm{CD} 137^{\mathrm{LO}}$ monocytes. G Graphs display metabolic flux analyses of $\mathrm{CD} 137^{\mathrm{HI}}$ and $\mathrm{CD} 137^{\mathrm{LO}}$ monocytes $(n=3)$. Extracellular acidification rate (ECAR, left panel), was measured as surrogate for aerobic glycolysis under basal conditions, in response to glucose (=basal glycolysis), and upon blocking mitochondrial ATP generation by oligomycin (=maximum glycolysis). 2-DG inhibits glycolysis and blunts ECAR activity. Oxygen consumption (OCR, right panel) was measured as marker for mitochondrial oxidative phosphorylation under basal conditions and in response to the indicated mitochondrial inhibitors. Changes after oligomycin, FCCP, and Antimycin/Rotenone are indicative for respiration linked to ATP production, and maximal respiratory capacity. H Basal glycolysis (left panel) and basal respiration (right) panel were determined for $\mathrm{CD} 137^{\mathrm{HI}}$ and $\mathrm{CD} 137^{\mathrm{LO}}$ monocytes $(n=3)$. I Basal OCR/ECAR ratio is plotted for individual $\mathrm{CD} 137^{\mathrm{HI}}$ and $\mathrm{CD} 137^{\mathrm{LO}}$ monocytes. J Glycolytic capacity (left panel) and spared respiratory capacity (right panel) were determined for $\mathrm{CD} 137^{\mathrm{HI}}$ and $\mathrm{CD} 137^{\mathrm{LO}}$ monocytes $(n=3)$. K Proton leak (left panel) and coupling efficacy (right panel) were determined for $\mathrm{CD} 137^{\mathrm{HI}}$ and $\mathrm{CD} 137^{\mathrm{LO}}$ monocytes $(n=3)$. ${ }^{*} p<0.05 ; * * p<0.01 ; * * * p<0.001$.

reprogramming TAMs represents a promising strategy for positively instrumentalizing them. This approach is based on the plasticity of monocytes/macrophages, whose different phenotypes form a continuum between an antitumoral M1 and a rather pro-tumoral M2 phenotype. In fact, intrinsic tumoricidal capacity is retained in those M2-like TAMs and can be reactivated in preclinical models by disrupting M2-promoting signals or by interfering with immunological checkpoints [18, 34]. Here, we wanted to evaluate, whether CD137 stimulation by agonistic anti-CD137 antibodies holds the potential to bolster the monocytes' tumoricidal activity, especially in view of a combination with tumor-targeting mAbs [9].

Self-evidently, one prerequisite for such CD137-directed approach is the presence of CD137 on patient-derived monocytes. Similar to findings in T-cells isolated from patients with ovarian cancer or melanoma, CD137 expression levels were elevated on monocytes from CLL and MM patients (Fig. 4A) [35]. Moreover, CD137 ${ }^{\mathrm{HI} / \mathrm{LO}} \mathrm{CLL}$ or MM monocytes share similar features as their healthy donor-derived counterparts in terms of phagocytosis (Fig. 3B), phenotypic markers (i.e., CD11b, CD32, CD64, $\mathrm{CD} 86$, and $\mathrm{CD} 120 \mathrm{~b}$ ), and their metabolic repertoire (i.e., GLUT1, HK2, CD36, CPT1a, Mitotracker, and TMRE) (Supplementary Fig. 3). Next, we stimulated CD137 on healthy donor-derived monocytes by using an agonistic anti-CD137 mAb (clone 4B4-1) and tested for changes of the metabolic phenotype. Metabolic flux analyses revealed an upregulation of both glycolytic (e.g., basal glycolysis and glycolytic reserve) and OXPHOS (e.g., basal respiration) parameters (Fig. 4B, Supplementary Fig. 4). Overall, the monocytes' bioenergetics shifted to a more metabolically active state leading also to an expected skewing of the ADP-to-ATP ratio towards the latter (Fig. 4C). In line with this enhanced metabolic turnover, uptake of the bioenergetic substrates, such as glucose and free fatty acids as well as mitochondrial biogenesis were found enhanced upon CD137 triggering (Fig. 4D).

Next, we assessed the impact of CD137 activation on the monocytes' tumoricidal potency. Engaging CD137, resulted in an amplified elimination of the MM cell line OPM-2 presumably through mechanisms of ADCP and ADCC. This was also true when co-applying Daratumumab. Similar phenomena were documented in experimental setups using primary MM-cells and autologous bone marrow-derived macrophages or when testing the B-cell malignancy-derived cell lines HG-3 (CLL) and Raji (Burkitt lymphoma) or primary CLL cells in presence of Rituximab (Fig. 4E, Supplementary Fig. 5A, B). It is well-established that the interaction of PD-L1 (on tumor cells) with PD-1 on monocytes and macrophages drives their anergy [24, 36]. Consequently, Rituximab did not significantly boost tumoricidality, when using PD-L1-overexpressing Raji cells as a target. However, combined treatment with Rituximab and CD137 activation efficiently antagonized the negative impact of PD-L1 overexpression leading to a significantly improved elimination of Raji cells (Fig. 4F, Supplementary Fig. 5C).

\section{Monocytes/macrophages acquire M1-like features upon stimulation of CD137}

We performed RNA-seq analyses of monocytes treated with or without activating anti-CD137 antibodies (GSE171109). The unsupervised PCA separated treated from untreated monocytes, thus supporting the notion that triggering CD137 initiates a rather specific gene expression pattern (Supplementary Fig. 6A). Subjecting the genes upregulated in response to CD137 activation to GSEA, demonstrated an enrichment of genes that are linked to the generation of monocyte-derived macrophages, M1 polarization, inflammatory signaling, metabolism, and phagocytosis (Fig. 5A, B, Supplementary Fig. 6B). 

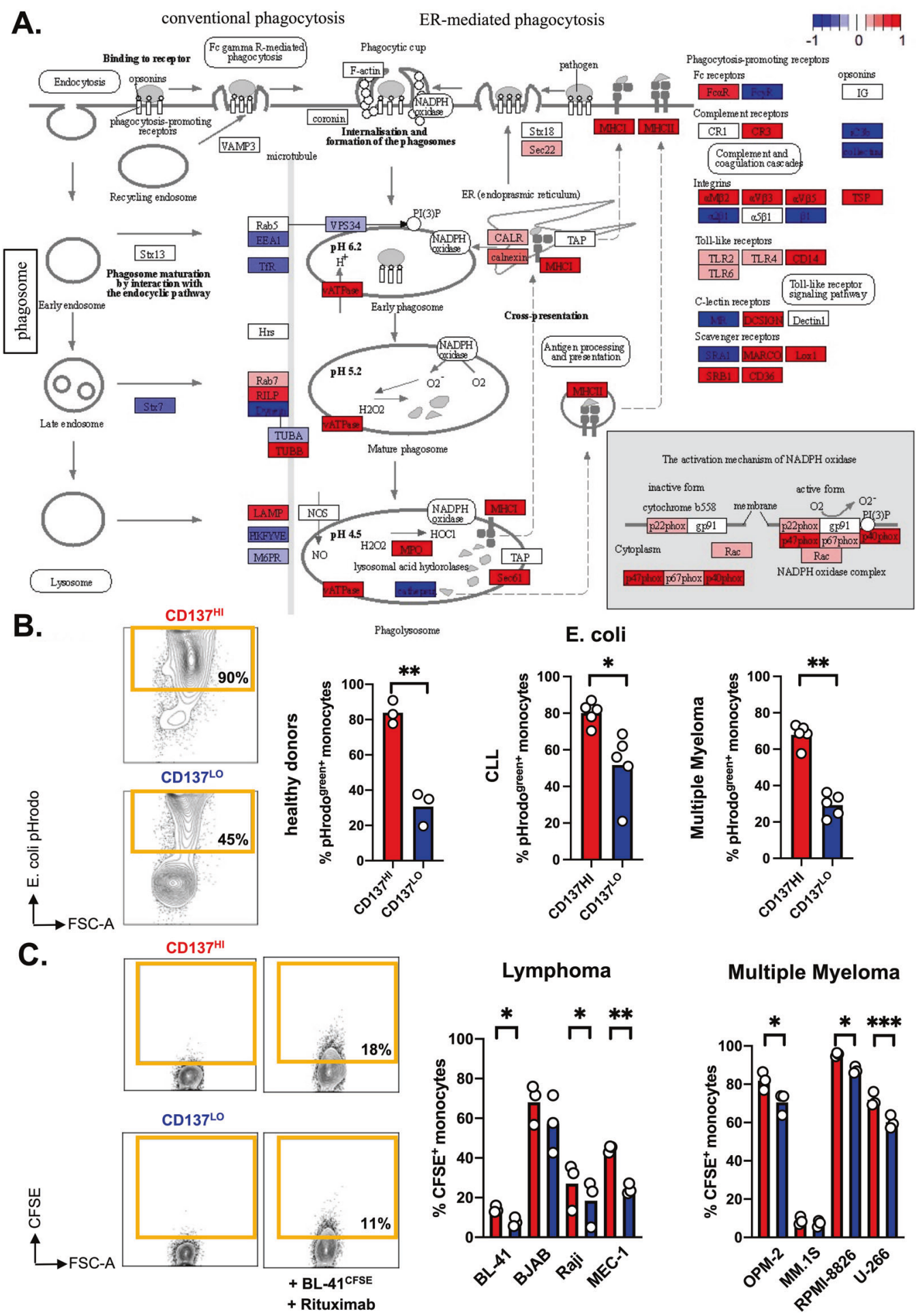

\section{Multiple Myeloma}

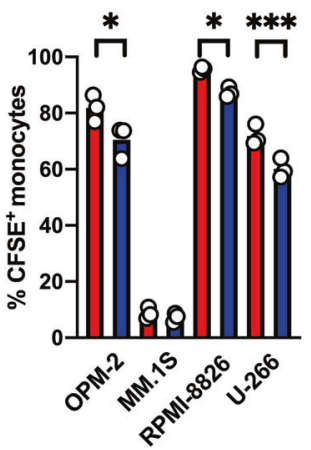

Fig. $3 \mathrm{CD}^{\mathrm{C}} 7^{\mathrm{HI}}$ monocytes exhibit enhanced phagocytic activity. A Differential gene expression of $\mathrm{CD} 137^{\mathrm{HI}}$ and $\mathrm{CD} 137^{\mathrm{LO}}$ monocytes shows enrichment of genes upregulated in $\mathrm{CD} 137^{\mathrm{HI}}$ monocytes (red) in the KEGG Phagosome Reference pathway (map04145). B Phagocytosis of $\mathrm{pHrodo}^{\mathrm{TM}}$-conjugated $E$. coli by $\mathrm{CD} 137^{\mathrm{HI}}$ and $\mathrm{CD} 137^{\mathrm{LO}}$ monocytes from healthy donors $(n=3)$ and patients with chronic lymphocytic leukemia (CLL, $n=5)$ or multiple myeloma $(n=5)$. Left panel shows representative FACS-based analyses of healthy donor-derived

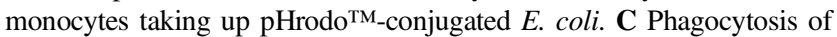

CFSE-stained tumor cells in presence of therapeutic antibodies by $\mathrm{CD} 137^{\mathrm{HI}}$ and $\mathrm{CD} 137^{\mathrm{LO}}$ monocytes as analyzed by FACS. The left panel shows representative data for the uptake of the Burkitt lymphoma cell line BL-41 in presence of Rituximab. Phagocytosis by $\mathrm{CD} 137^{\mathrm{HI}}$ and $\mathrm{CD} 137^{\mathrm{LO}}$ monocytes $(n=3)$ of $\mathrm{CD} 20^{+}$B-cell-derived non-Hodgkin lymphoma cell lines (in presence of Rituximab) and of $\mathrm{CD} 38^{+}$multiple myeloma cell lines (in presence of Daratumumab). $* p<0.05$; $* * p<$ $0.01 ; * * * p 0.001$. 
A.

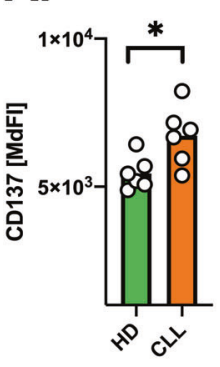

C.

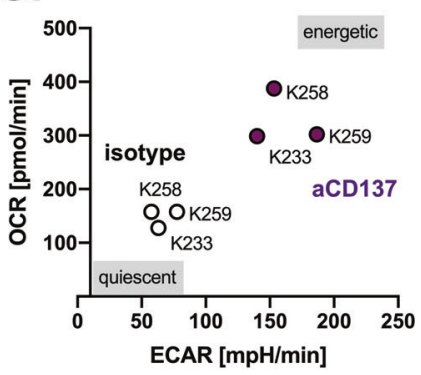

E.
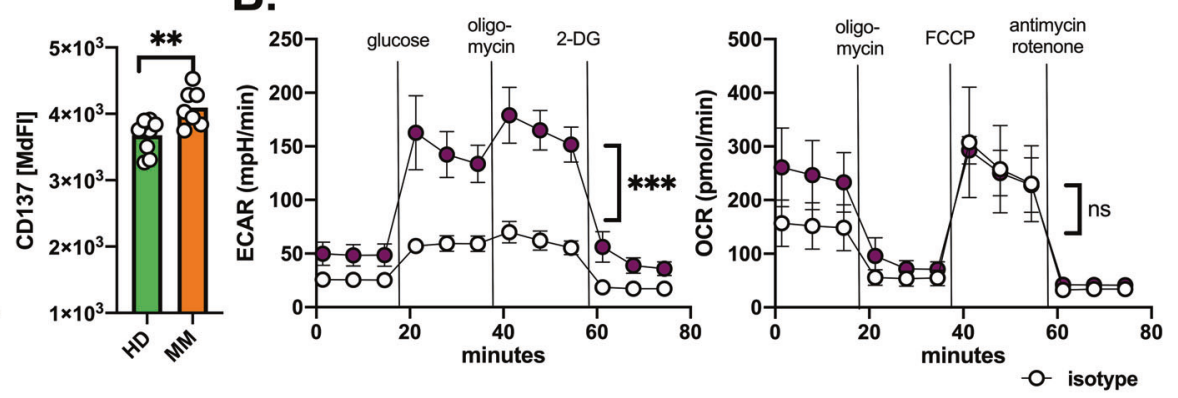

D.
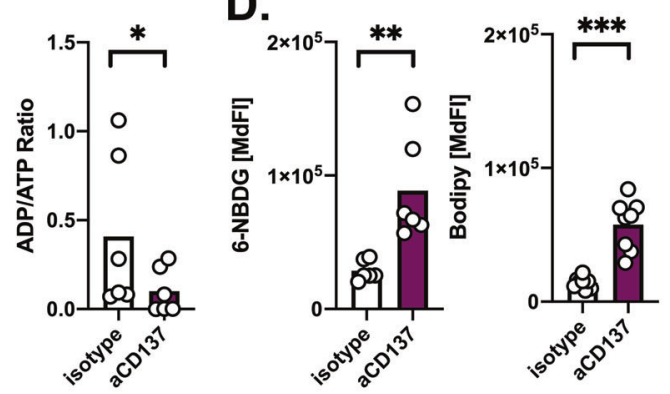

Multiple Myeloma
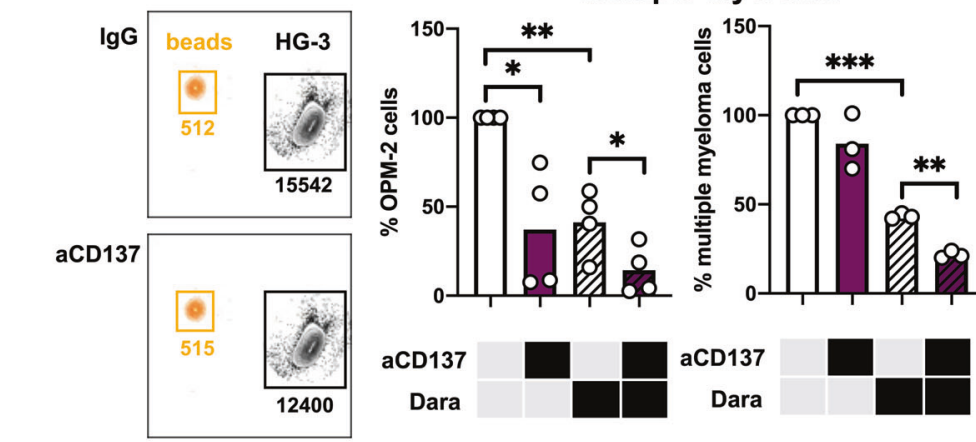

F.
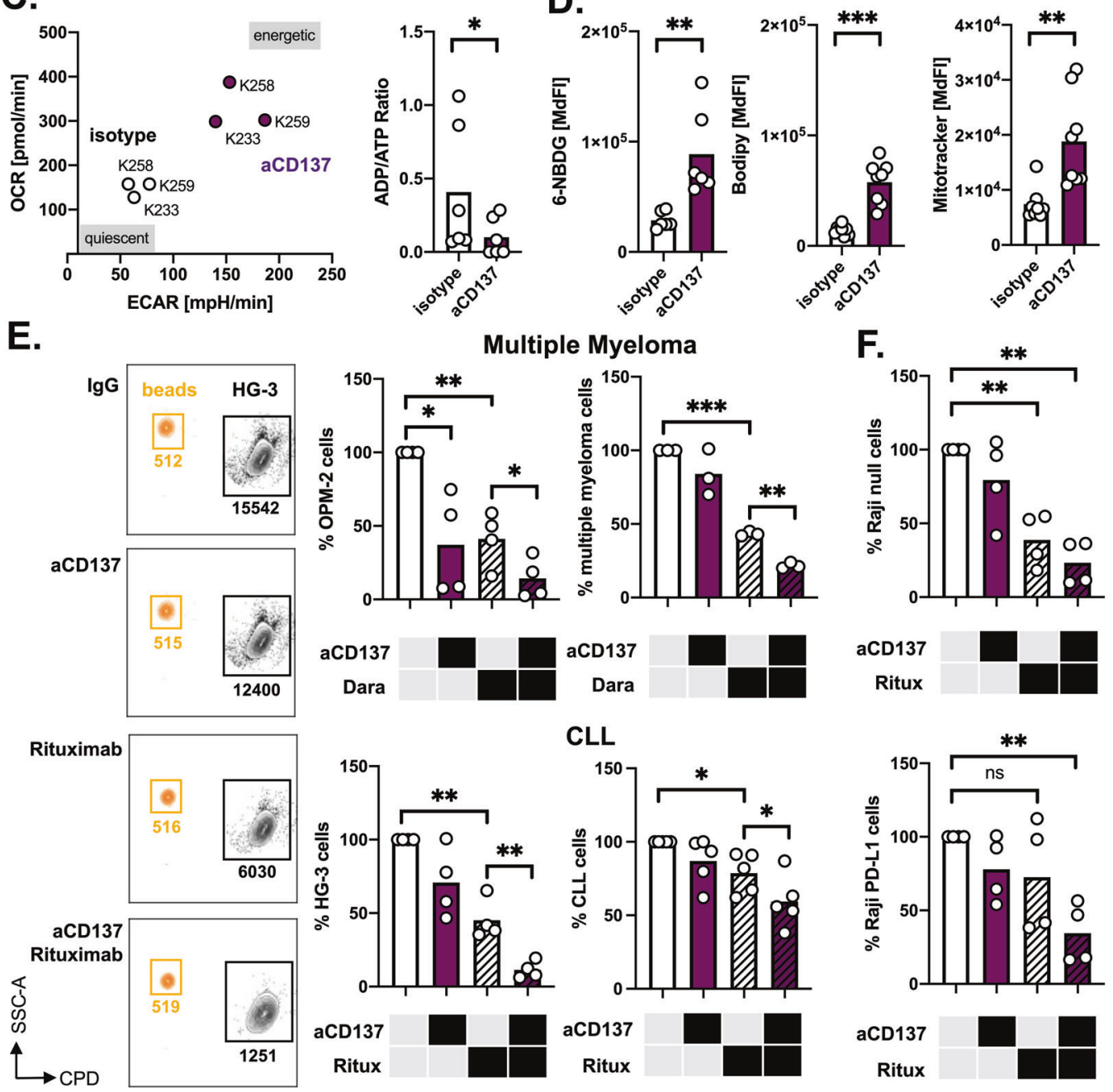

CLL

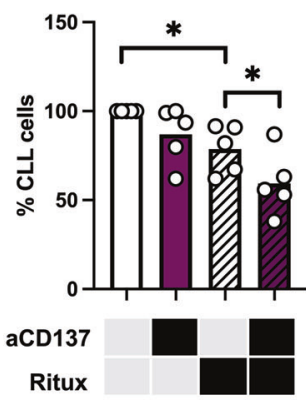

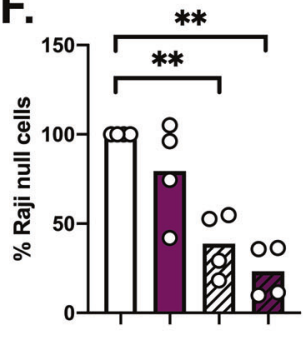
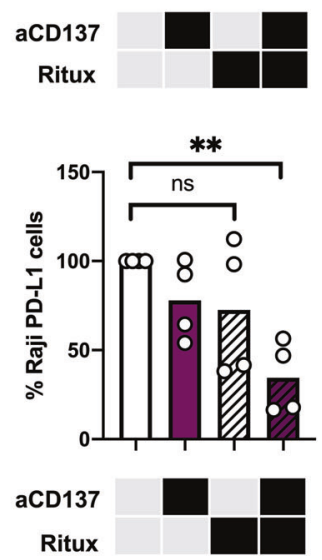

Next, monocytes were cultured under M1 and M2 macrophage-polarizing conditions using GM-CSF and MCSF respectively, or in presence of CD137-stimulating antibodies. Analyzing the surface expression of CD11b, CD14, and CD163 demonstrated that CD137 activation might mimic polarization towards a (rather tumoricidal) $\mathrm{M} 1$ phenotype that is characterized by upregulation of $\mathrm{CD} 11 \mathrm{~b}$ and downregulation of CD14 and CD163 (Fig. 5C) [37]. Equivalent effects were observed, when treating CLL or MM patient- derived monocytes with anti-CD137 mAbs (Supplementary Fig. 7). Moreover, we assessed production of the prototypical cytokines IL-10 (for M2) and IL-12 (for M1) and again observed that both GM-CSF and CD137 activation promoted IL-12 levels (Fig. 5D). We detected an increased production of the proinflammatory cytokines IL- 6 and TNF- $\alpha$, which was accompanied by the significant promotion of T-cell proliferation, when T-cells were co-cultured with previously CD137-stimulated monocytes (Fig. 5E, F). 
Fig. 4 CD137 stimulation on monocytes increases metabolic activity and tumoricidal capacity. A CD137 expression was quantified by FACS on healthy donor-derived monocytes (HD) and monocytes from CLL $(n=6)$ and multiple myeloma $(n=7)$ patients. B Extracellular flux analyses were performed with monocytes treated with the 4B4-1 CD137-stimulating monoclonal antibody or a control antibody $(n=3)$ for 4 days. ECAR (left panel) and OCR (right panel) levels were measured under baseline conditions and upon injection of the indicated substances. C Basal ECAR/OCR ratio (left panel) of control vs. anti-CD137 mAb-treated monocytes $(n=3)$ is plotted showing a shift from quiescent to metabolically more active cells. The right panel displays the ratio of ADP/ATP of control vs. anti-CD137 mAb-treated monocytes $(n=6)$. D Glucose uptake assessed by 6NBDG staining $(n=6)$, fatty acid uptake assessed by BODIPYTM FL C16 staining $(n=8)$, and mitochondrial biomass assessed by MitoTracker staining $(n=8)$ of control vs. anti-CD137 mAb-treated monocytes were analyzed by FACS. E Killing of CPD-stained tumor cells in presence or absence of a therapeutic antibody (Dara $=$ Daratumumab, Ritux $=$ Rituximab) by monocytes pretreated with either control or anti-CD137 mAb for 3 days. Left panels show representative FACS plots of surviving lymphoma cells (HG-3) after $18 \mathrm{~h}$ of coculture. Counting beads were used for normalization of per sample tumor cell counts. Upper panels showing killing of multiple myeloma cell lines OPM-2 $(n=4)$ and of primary multiple myeloma cells cocultured with autologous bone marrow-derived macrophages $(n=3)$ and the lower panels show killing of the CLL cell line HG-3 $(n=4)$ and of primary CLL cells by autologous monocytes $(n=5)$. Survival of tumor cells co-cultured with control mAb-treated monocytes without therapeutic antibody are set to $100 \%$. F Experimental setup as described in $\mathbf{E}$ using a PD-L1 overexpressing Raji cell line (lower panel) and the corresponding control Raji null (upper panel) $(n=4)$. Bars indicate the standard error of mean. $* p<0.05 ; * * p<0.01 ; * * * p$ $<0.001$.

In order to evaluate, whether CD137 signaling holds the potential to repolarize (already) differentiated M2 macrophages, M-CSF-generated M2-like macrophages were treated with activating anti-CD137 mAbs. Triggering CD137 promoted CD11b expression and suppressed CD14 and CD163 on M2 macrophages, thereby mimicking the effects of GM-CSF that shifts macrophages towards an M1like phenotype (Fig. 5G). Furthermore, we noticed enhanced glucose consumption and lactic acid release suggesting a proglycolytic shift, which is typically seen in classically activated M1 macrophages (Fig. 5H) [38].

\section{CD137-mediated effects depend on ERK signaling}

ERK controls numerous molecules involved in translation regulation. Data from previous studies in T-cells suggest that ERK is involved in the downstream signaling of CD137 [39]. Moreover, ERK activation has been shown to convert suppressive macrophages towards a tumoricidal phenotype [40]. In line with the findings in T-cells, we observed ERK phosphorylation in monocytes upon triggering CD137 (Fig. 6A). For the following functional assessment of ERK, we used the pharmacological ERK inhibitor Ravoxertinib in non-cytotoxic dosages (Fig. 6B).
Ravoxertinib significantly mitigated in a dose-dependent manner the CD137-mediated effects on the monocytes' cell surface expression of CD11b, CD14, and CD163 (Fig. 6C). In addition, it prevented their metabolic switch towards aerobic glycolysis as well as the promotion of IL-12 production (Fig. 6D, E). Taking into consideration potential off-target effects of Ravoxertinib, we tested SCH772984, a second extremely selective ERK inhibitor, and confirmed the impact of ERK inhibition on the phenotypic and metabolic transition of monocytes treated with anti-CD137 mAbs (Supplementary Fig. 8). Finally, ERK inhibition fully abolished our previously noticed added tumoricidal value of combining CD137 activation with mAbs against tumor antigens. Engaging CD137 in presence of Ravoxertinib did not improve anymore clearance of the $\mathrm{CD} 38^{+} \mathrm{MM}$ cell line MM.1S treated with the anti-CD38 mAb Daratumumab (Fig. 6F).

\section{Discussion}

Immunotherapeutic concepts have heralded a new era of cancer treatment leading to long-term survival and even cure [1]. Despite this tremendous success, primary resistance and/or acquired resistance during therapy is regularly observed in cancer patients [41]. Poor responses towards immunotherapy are partly attributed to the complex and dynamic nature of the tumor microenvironment. Myeloid cells, such as TAMs or myeloid-derived suppressor cells represent major components of the tumor microenvironment and their abundance can be associated with poor prognosis (e.g., in $\mathrm{MM}$ or in aggressive lymphoma) [32, 33]. However, owed to their plasticity, intrinsic tumoricidal capacity is retained in TAMs and efficiently reactivated by disrupting tolerance-promoting signals or by interfering with negative immunological checkpoints, such as CD47 or PD-L1 $[18,19,36]$. In addition to blocking inhibitory signals, engaging stimulatory receptors on immune cells, such as CD137, which has been mainly studied in T and NK cells, represent an area of intensive research [5].

Here, we demonstrate that CD137 is expressed on circulating monocytes, which is in line with previous observations [42]. Moreover, we show that $\mathrm{CD} 137^{\mathrm{HI}}$ monocytes are characterized by a distinct phenotypic and transcriptomic profile. Interestingly, we observed an overrepresentation of classical monocytes within the $\mathrm{CD} 137^{\mathrm{HI}}$ monocyte population accompanied by a functional and phenotypical overlap between both. In line with previous findings in classical monocytes, $\mathrm{CD} 137^{\mathrm{HI}}$ monocytes also exhibited an enhanced carbohydrate metabolism and phagocytic capacity. Furthermore, in transcriptome analyses, $\mathrm{CD} 137^{\mathrm{HI}}$ monocytes were predicted to be of proinflammatory phenotype, which is a 

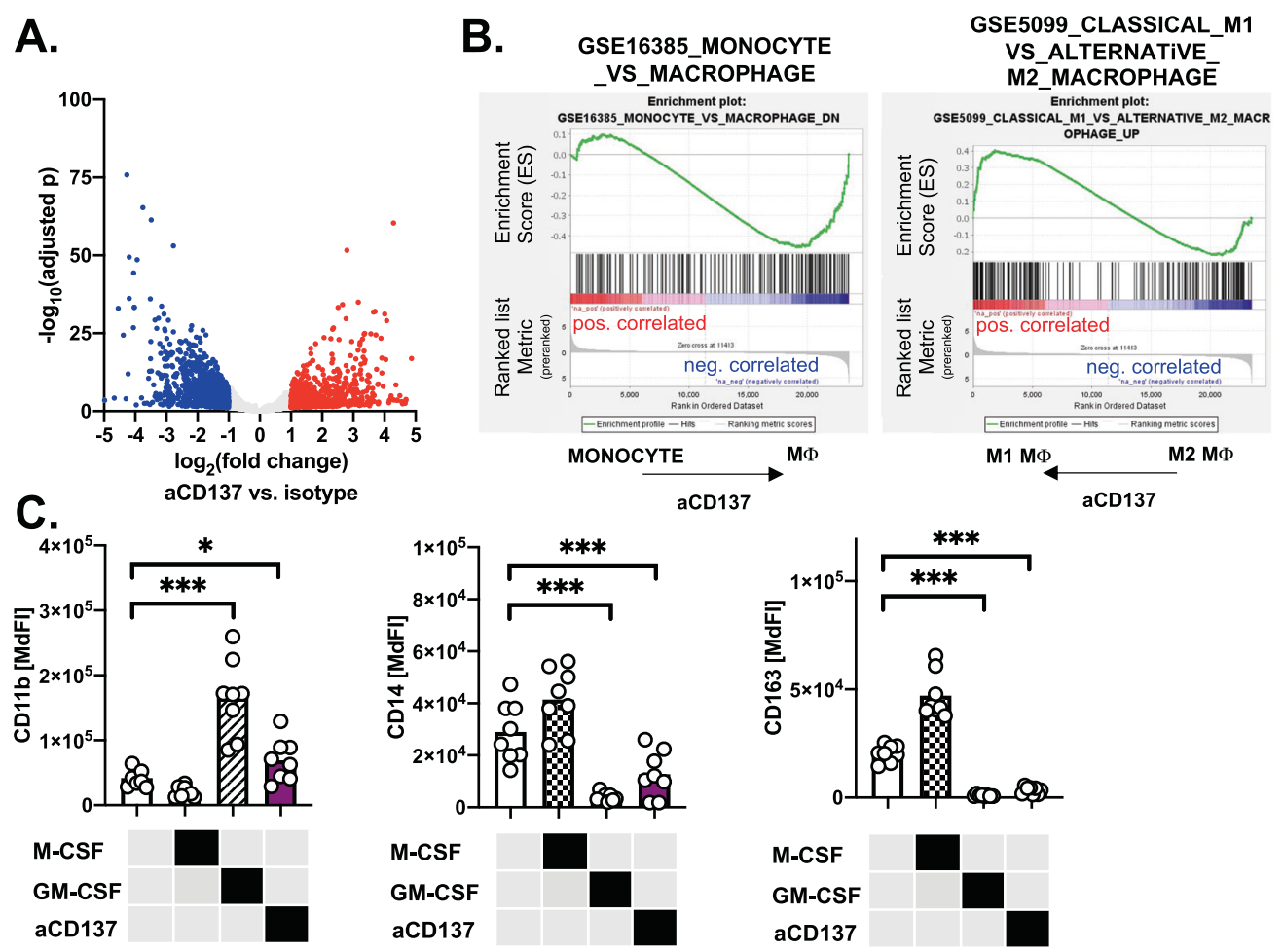

D.
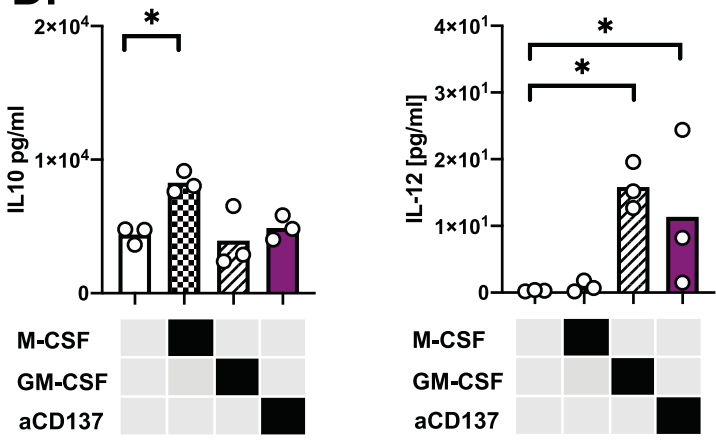

E.
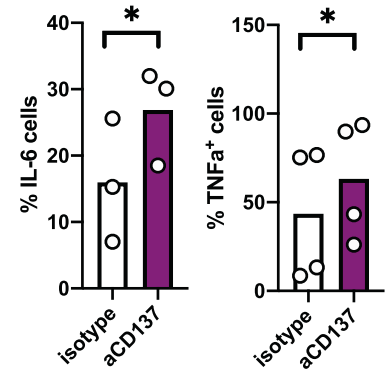

F.
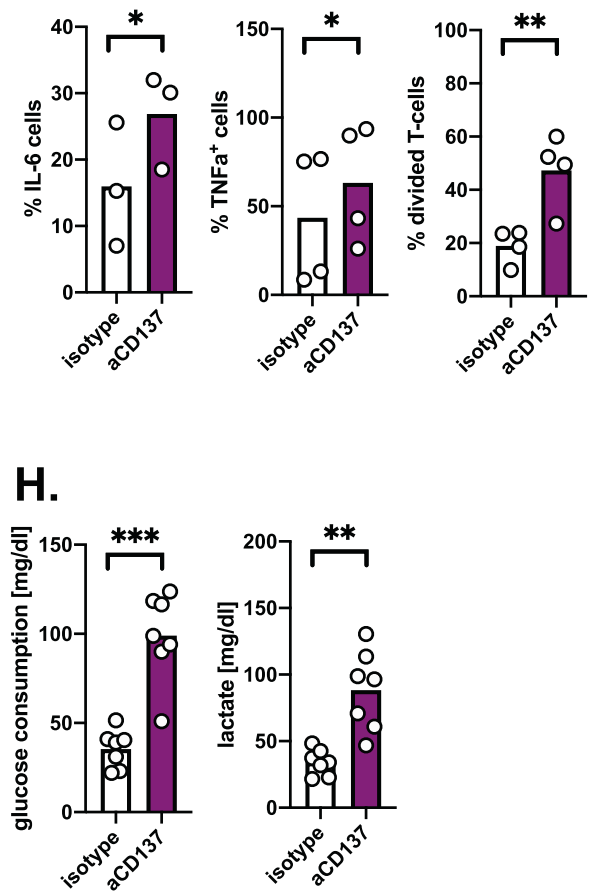

H.
G.

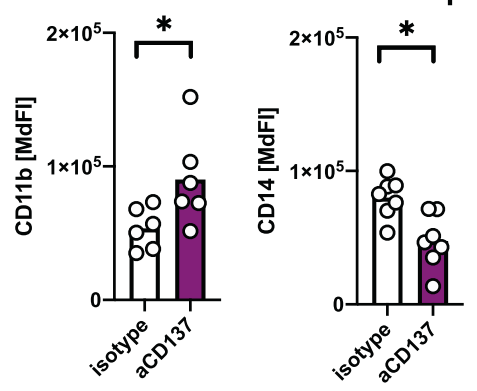

M2 polarised M $\Phi$

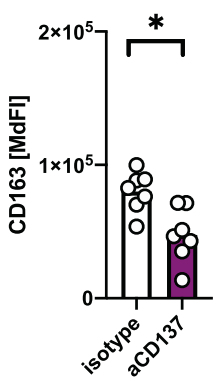

known feature of classical monocytes [43, 44]. In fact, these features also hold true for M1 polarized monocytes. Yet, we could not unequivocally assign $\mathrm{CD} 137^{\mathrm{HI}}$ cells to a $\mathrm{M} 1$ or an M2 phenotype. This is in line with the general reassessment of the M1/M2 paradigm pointing towards the co-existence of M1 and M2 signatures with the resultant mixed phenotypes rather depending on the balance of activatory and inhibitory signals [45]. Genes that were involved in bioenergetics, proinflammatory activity, and phagocytosis were found enriched in the $\mathrm{CD} 137^{\mathrm{HI}}$ population. Subsequent metabolic analyses revealed a proglycolytic phenotype and an increased glycolytic reserve in $\mathrm{CD} 137^{\mathrm{HI}}$ as compared to $\mathrm{CD} 137^{\mathrm{LO}}$ monocytes. Enhanced glycolysis enables them to meet their energetic demands for carrying out their effector 
Fig. 5 CD137 stimulation on monocytes induces differentiation of macrophages with M1-like features and increased proinflammatory properties. A Volcano plot of differentially expressed genes showing genes (each dot represents one gene) with at least twofold upregulation (red) or downregulation (blue) in anti-CD137 mAb-treated monocytes, as well as a high number of significantly differentially expressed genes $(q<0.1: 7309$ genes). B Gene set enrichment analysis of differential gene expression reveals negative enrichment of genes associated with undifferentiated monocytes (left panel, NES $=-1.3402828, \quad p=0.03, q=0.12$ ) and significant enrichment of M1 polarization-associated genes (right panel, NES = $1.2730565, p=0.027 q=0.18)$ in anti-CD137 mAb-treated monocytes. C Expression of CD11b, CD14, and CD163 was quantified by FACS on monocytes treated for 6 days with a control antibody, MCSF (50 ng/ml), GM-CSF (50 ng/ml), or agonistic anti-CD137 mAbs $(n=8)$. D IL-10 and IL-12 production was measured by ELISA in the supernatants of monocytes treated for 5 days with a control antibody, M-CSF (50 ng/ml), GM-CSF (50 ng/ml), or agonistic anti-CD137 $\mathrm{mAbs}$ and subsequently stimulated with $100 \mathrm{ng} / \mathrm{ml}$ LPS for $24 \mathrm{~h}(n=$ $3)$. E IL-6 $(n=3)$ and TNF- $\alpha(n=4)$ positive $\left({ }^{+}\right)$monocytes were determined by FACS among cells treated for 4 days with a control antibody or agonistic anti-CD137 mAbs and subsequently stimulated with $100 \mathrm{ng} / \mathrm{ml}$ LPS for $24 \mathrm{~h}$. F Proliferation of T-cells in presence of activation beads (anti-CD2, -CD3, and -CD28 bead-coupled antibodies) co-cultured with HD monocytes (ratio 1:1) pretreated with either control antibody or an anti-CD137 mAb for 4 days $(n=5)$. G Expression of CD11b, CD14, and CD163 was quantified by FACS on monocytes $(n=7)$ treated for 4 days with M-CSF followed by a 3day treatment with a control or anti-CD137 mAb. H Glucose consumption and lactate production were determined in supernatants of monocytes treated as in $\mathbf{H}$ using a HITADO SuperGL. ${ }^{*} p<0.05$; $* * p<0.01 ; * * * p<0.001$; NES normalized enrichment score.

functions, such as phagocytosis and cytokine production [46]. A proglycolytic shift has been shown to be paramount for the monocytes' and macrophages' proinflammatory activation [47]. However, it needs to be pointed out that complex stimuli elicit a more complex metabolic response leading to parallel stimulation of both glycolysis and OXPHOS [48]. In line with their metabolic and transcriptomic profile, $\mathrm{CD} 137^{\mathrm{HI}}$ monocytes displayed a superior phagocytic capacity in terms of bacterial pathogens as well as lymphoma or MM cell lines that were pretreated with anti-CD20 and anti-CD38 mAbs [24]. Equivalent findings were recently described in hepatocellular carcinoma patientderived T-cells, with the $\mathrm{CD} 137^{\mathrm{HI}} \mathrm{CD} 8^{+}$subset displaying a superior antitumor reactivity and expressing, amongst others, higher IFN- $\gamma$ levels [49]. Similar to T-cells retrieved from patients with ovarian cancer or melanoma, we detected elevated CD137 expression levels on circulating monocytes from CLL and MM patients [35].

Using activating antibodies against CD137 on monocytes led to an upregulation of both glycolysis and OXPHOS, which is also observed in $\mathrm{CD}^{+} \mathrm{T}$-cells treated with anti-CD137 mAbs [25]. Overall increased metabolic fitness was accompanied by the monocytes' superior ability to ingest MM and lymphoma cell lines that are co-treated with anti-CD20 and anti-CD38 antibodies, respectively.
These findings are in line with data from preclinical lymphoma and MM models in which CD137 stimulation enhanced the anti-lymphoma and -myeloma activity of antiCD20 and anti-CD38 antibodies $[9,50,51]$. Remarkably, PD-L1-mediated monocyte inhibition could be overridden by triggering $\mathrm{CD} 137$, which could contribute to the synergistic antitumor activity reported in patients with advanced solid tumors that were treated with a combination of PD-1 blockade and CD137 stimulation [24, 52].

Being fully aware of the limitations of the M1/M2 paradigm, we used an in vitro polarization model, in which we generated (antitumoral) M1 and (pro-tumoral) M2 macrophages [45]. Treatment with agonistic CD137 mAbs mimicked M1-polarizing conditions. The notion that CD137 stimulation might hold the potential to skew the M1/M2 balance within the tumor microenvironment towards a proinflammatory M1 profile was further supported by the finding that CD137 stimulation resets phenotypic and metabolic M2-features in already differentiated M2-like macrophages. Moreover, TAMs retrieved from MM patient-derived bone marrow exhibited increased antitumoral activity upon CD137 activation. Accordingly, CTX-471 a novel CD137 agonist with remarkable efficacy in preclinical models of large tumors resulted in a repolarization of tumor microenvironment-resident macrophages towards an M1 phenotype [53].

CD137 stimulation induces rapid downstream activation of the ERK pathway in T-cells, which we also observed in monocytes [39]. In fact, ERK signaling has been previously linked to the conversion of suppressive macrophages towards a pro-immunogenic phenotype [40]. Consequently, blocking ERK signaling in monocytes abolished the immunometabolic effects triggered by CD137 stimulation including enhanced aerobic glycolysis, IL-12 production, and ADCP.

Taken together, we describe an as yet unknown role of CD137 for monocytes/macrophages. Nowadays, targeting CD137 has gained momentum in preclinical and clinical studies based on its ability to drive NK- and Tcell-based responses. Here, we initially reveal that $\mathrm{CD} 137^{\mathrm{HI}}$ monocytes hold a superior tumoricidal potential. Next, we report that activating CD137 on monocytes/ macrophages triggers their functional reprogramming towards a metabolically more active, M1-like phenotype with greater antitumor potential, thereby explaining observations from clinical trials and preclinical models that the combination of CD137 agonists and therapeutic antibodies can be effective in malignant diseases. Our findings help to better understand the effects of CD137 activation on the tumor microenvironment, which is critical for its optimal application, selection of biological read-outs in studies, and the choice of therapeutic combination partners. 


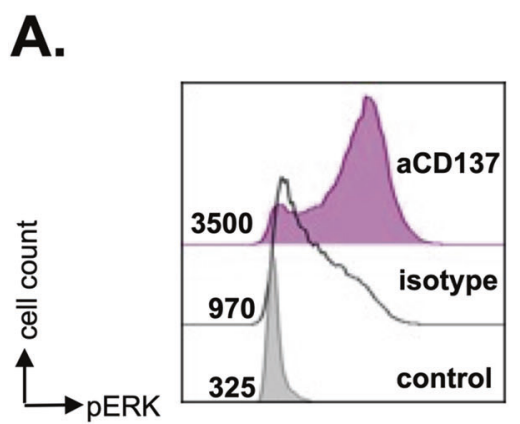

B.
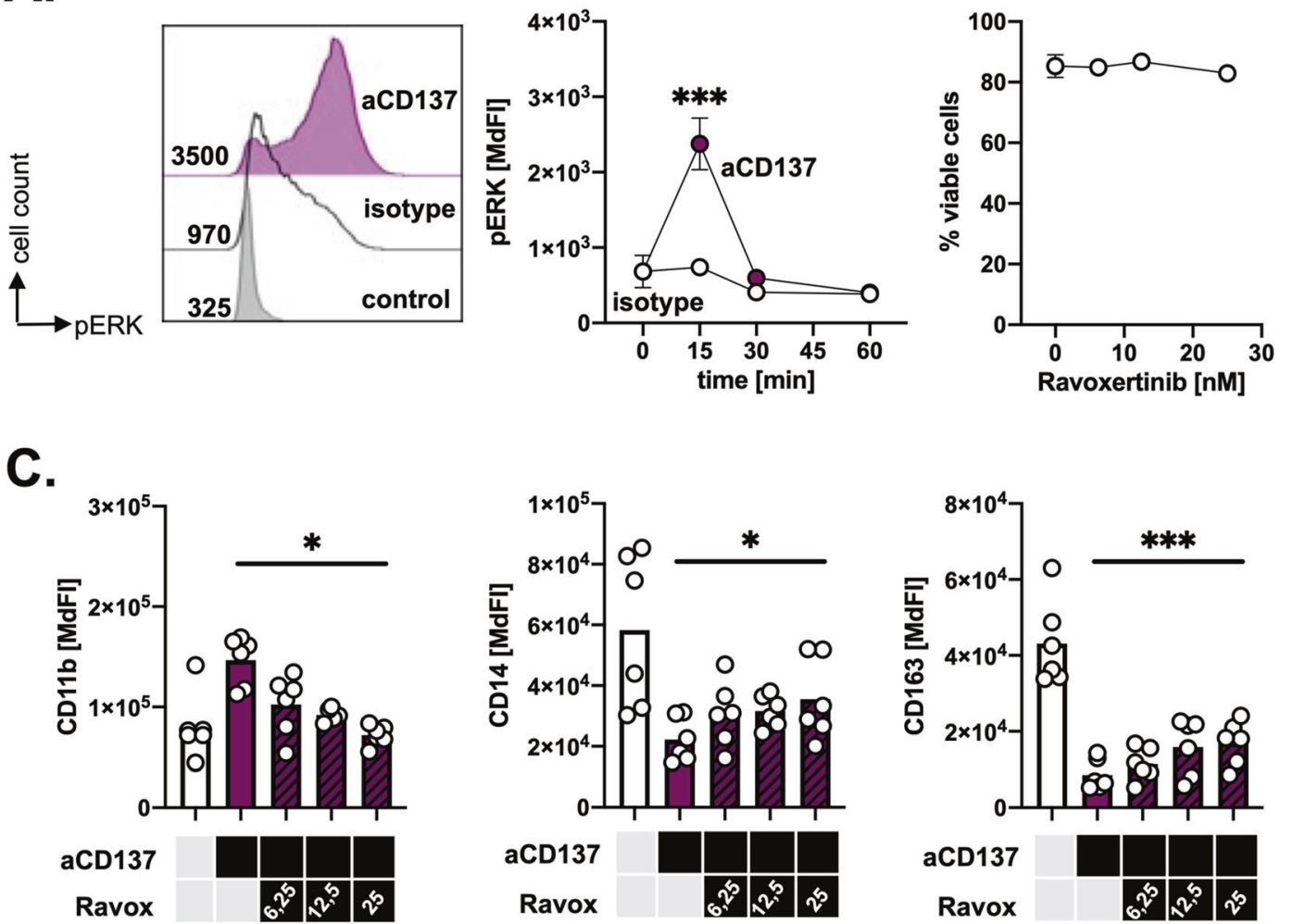

D.

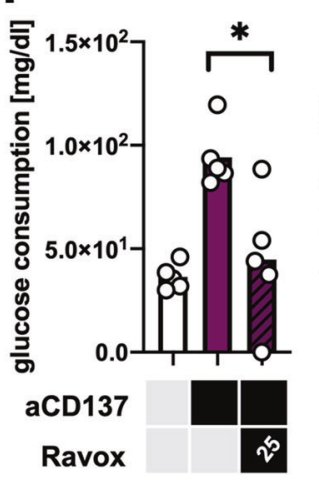

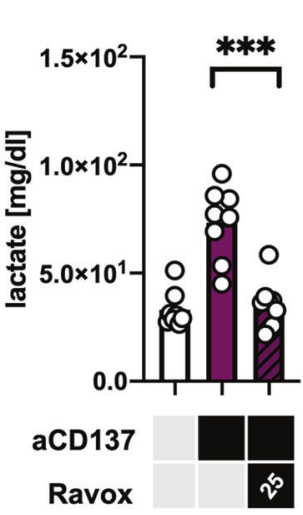

Ravox
E.

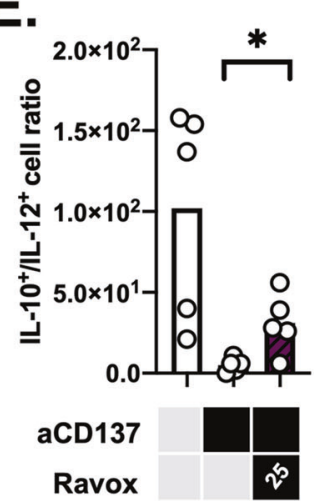

F.

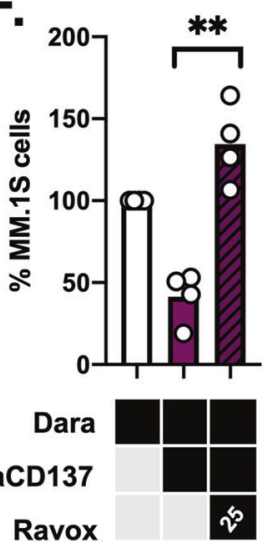

Fig. 6 CD137 activation-mediated immunometabolic effects depend on ERK1/2 signaling. A pERK staining in human monocytes upon treatment with either 4B4-1 an activating anti-CD137 mAb or an isotype control as determined by FACS. Left panel shows representative pERK staining after $15 \mathrm{~min}$ of activation. Right panel shows pERK levels at indicated timepoints after activation. $(n=4)$. B Viability of monocytes cultured with indicated concentrations of the ERK inhibitor Ravoxertinib for 4 days as determined by FACS $(n=6)$. C Expression of CD11b, CD14, and CD163 was determined on monocytes treated with either control antibody, anti-CD137 mAb or a combination of anti-CD137 $\mathrm{mAb}$ and the indicated concentrations (in $\mathrm{nM}$ ) of Ravoxertinib for 4 days $(n=6)$. D Glucose consumption and lactate production were determined in the supernatants of monocytes treated with either control antibody, anti-CD137 mAb or a

combination of anti-CD137 mAb and $25 \mathrm{nM}$ of Ravoxertinib for 4 days $(n=6)$. $\mathbf{E}$ The ratio of IL- $10^{+} / \mathrm{IL}-12^{+}$monocytes as determined by an IL-10/12-secretion assay using FACS. Monocytes $(n=5)$ were treated with either control antibody, anti-CD137 mAb or a combination of anti-CD137 mAb and $25 \mathrm{nM}$ of Ravoxertinib for 4 days and subsequently activated with $1 \mu \mathrm{g} / \mu \mathrm{l}$ LPS and $2 \mu \mathrm{g} / \mu \mathrm{l}$ Resiquimod for $20 \mathrm{~h}$ before secretion assay was performed. F Elimination of MM.1S tumor cells in the presence of therapeutic antibody Daratumumab by monocytes pretreated with either control antibody, anti-CD137 mAb or a combination of anti-CD137 mAb and $25 \mathrm{nM}$ of Ravoxertinib for 3 days. Survival was analyzed after $18 \mathrm{~h}$ of coculture. Survival rate of MM.1S cells in coculture with isotype-treated monocytes is set to $100 \%$. $* p<0.05 ; * * p<0.01 ; * * * p<0.001$. 
Author contributions AS performed experiments, analyzed data, and helped writing the manuscript. HB, CG, FN, SV, and MP helped designing the study and performed experiments. MF and MK analyzed data. AM helped designing the study. DM designed the study, analyzed data, and wrote the manuscript.

Funding AS, HB, AM, and DM were supported by the Deutsche Forschungsgemeinschaft (SFB-TRR221). MF and MK were supported by the Era-Net grant 01KT1801. Open Access funding enabled and organized by Projekt DEAL.

\section{Compliance with ethical standards}

Conflict of interest The authors declare no competing interests.

Publisher's note Springer Nature remains neutral with regard to jurisdictional claims in published maps and institutional affiliations.

Open Access This article is licensed under a Creative Commons Attribution 4.0 International License, which permits use, sharing, adaptation, distribution and reproduction in any medium or format, as long as you give appropriate credit to the original author(s) and the source, provide a link to the Creative Commons license, and indicate if changes were made. The images or other third party material in this article are included in the article's Creative Commons license, unless indicated otherwise in a credit line to the material. If material is not included in the article's Creative Commons license and your intended use is not permitted by statutory regulation or exceeds the permitted use, you will need to obtain permission directly from the copyright holder. To view a copy of this license, visit http://creativecommons. org/licenses/by/4.0/

\section{References}

1. Yang Y. Cancer immunotherapy: harnessing the immune system to battle cancer. J Clin Investig. 2015;125:3335-7.

2. Wei SC, Duffy CR, Allison JP. Fundamental mechanisms of immune checkpoint blockade therapy. Cancer Discov. 2018;8: 1069-86.

3. Wolfl M, Kuball J, Ho WY, Nguyen H, Manley TJ, Bleakley M, et al. Activation-induced expression of CD137 permits detection, isolation, and expansion of the full repertoire of CD8 $+\mathrm{T}$ cells responding to antigen without requiring knowledge of epitope specificities. Blood. 2007;110:201-10.

4. Akhmetzyanova I, Zelinskyy G, Littwitz-Salomon E, Malyshkina A, Dietze KK, Streeck H, et al. CD137 agonist therapy can reprogram regulatory $\mathrm{T}$ Cells into cytotoxic CD4+ $\mathrm{T}$ cells with antitumor activity. J Immunol. 2016;196:484-92.

5. Makkouk A, Chester C, Kohrt HE. Rationale for anti-CD137 cancer immunotherapy. Eur J Cancer. 2016;54:112-9.

6. Wang $\mathrm{C}$, Lin $\mathrm{GH}, \mathrm{McPherson} \mathrm{AJ}$, Watts $\mathrm{TH}$. Immune regulation by $4-1 \mathrm{BB}$ and $4-1 \mathrm{BBL}$ : complexities and challenges. Immunol Rev. 2009;229:192-215.

7. Snell LM, Lin GH, McPherson AJ, Moraes TJ, Watts TH. T-cell intrinsic effects of GITR and 4-1BB during viral infection and cancer immunotherapy. Immunol Rev. 2011;244:197-217.

8. Milone MC, Fish JD, Carpenito C, Carroll RG, Binder GK, Teachey D, et al. Chimeric receptors containing CD137 signal transduction domains mediate enhanced survival of $\mathrm{T}$ cells and increased antileukemic efficacy in vivo. Mol Ther. 2009;17:1453-64.

9. Kohrt HE, Houot R, Goldstein MJ, Weiskopf K, Alizadeh AA, Brody J, et al. CD137 stimulation enhances the antilymphoma activity of anti-CD20 antibodies. Blood. 2011;117:2423-32.
10. Wilcox RA, Flies DB, Zhu G, Johnson AJ, Tamada K, Chapoval AI, et al. Provision of antigen and CD137 signaling breaks immunological ignorance, promoting regression of poorly immunogenic tumors. J Clin Investig. 2002;109:651-9.

11. Melero I, Shuford WW, Newby SA, Aruffo A, Ledbetter JA, Hellstrom KE, et al. Monoclonal antibodies against the 4-1BB T-cell activation molecule eradicate established tumors. Nat Med. 1997;3:682-5.

12. Srivastava RM, Trivedi S, Concha-Benavente F, Gibson SP, Reeder C, Ferrone S, et al. CD137 stimulation enhances cetuximab-induced natural killer: dendritic cell priming of antitumor T-cell immunity in patients with head and neck cancer. Clin Cancer Res. 2017;23:707-16.

13. Segal NH, Logan TF, Hodi FS, McDermott D, Melero I, Hamid O, et al. Results from an integrated safety analysis of urelumab, an agonist anti-CD137 monoclonal antibody. Clin Cancer Res. 2017;23:1929-36.

14. Segal NH, He AR, Doi T, Levy R, Bhatia S, Pishvaian MJ, et al. Phase I study of single-agent utomilumab (PF-05082566), a 4-1BB/CD137 agonist, in patients with advanced cancer. Clin Cancer Res. 2018;24:1816-23.

15. Yang L, Zhang Y. Tumor-associated macrophages: from basic research to clinical application. J Hematol Oncol. 2017;10:58.

16. Gul N, van Egmond M. Antibody-dependent phagocytosis of tumor cells by macrophages: a potent effector mechanism of monoclonal antibody therapy of cancer. Cancer Res. 2015;75: 5008-13.

17. Singhal S, Stadanlick J, Annunziata MJ, Rao AS, Bhojnagarwala PS, O'Brien S, et al. Human tumor-associated monocytes/macrophages and their regulation of $\mathrm{T}$ cell responses in early-stage lung cancer. Sci Transl Med. 2019;11:479.

18. Gutierrez-Gonzalez A, Martinez-Moreno M, Samaniego R, Arellano-Sanchez N, Salinas-Munoz L, Relloso M, et al. Evaluation of the potential therapeutic benefits of macrophage reprogramming in multiple myeloma. Blood. 2016;128:2241-52.

19. Tseng D, Volkmer JP, Willingham SB, Contreras-Trujillo $\mathrm{H}$, Fathman JW, Fernhoff NB, et al. Anti-CD47 antibody-mediated phagocytosis of cancer by macrophages primes an effective antitumor T-cell response. Proc Natl Acad Sci USA. 2013;110:11103-8.

20. Beatty GL, Chiorean EG, Fishman MP, Saboury B, Teitelbaum UR, Sun W, et al. CD40 agonists alter tumor stroma and show efficacy against pancreatic carcinoma in mice and humans. Science. 2011;331:1612-6.

21. Wong KL, Tai JJ, Wong WC, Han H, Sem X, Yeap WH, et al. Gene expression profiling reveals the defining features of the classical, intermediate, and nonclassical human monocyte subsets. Blood. 2011;118:e16-31.

22. Hijdra D, Vorselaars AD, Grutters JC, Claessen AM, Rijkers GT. Differential expression of TNFR1 (CD120a) and TNFR2 (CD120b) on subpopulations of human monocytes. J Inflamm. 2012;9:38

23. Monaco G, Lee B, Xu W, Mustafah S, Hwang YY, Carre C, et al. RNA-seq signatures normalized by mRNA abundance allow absolute deconvolution of human immune cell types. Cell Rep. 2019;26:1627-40.

24. Qorraj M, Bruns H, Bottcher M, Weigand L, Saul D, Mackensen A, et al. The PD-1/PD-L1 axis contributes to immune metabolic dysfunctions of monocytes in chronic lymphocytic leukemia. Leukemia. 2017;31:470-8.

25. Choi BK, Lee DY, Lee DG, Kim YH, Kim SH, Oh HS, et al. 4-1BB signaling activates glucose and fatty acid metabolism to enhance CD8(+) T cell proliferation. Cell Mol Immunol. 2017; $14: 748-57$

26. Sukumar M, Liu J, Mehta GU, Patel SJ, Roychoudhuri R, Crompton JG, et al. Mitochondrial membrane potential identifies 
cells with enhanced stemness for cellular therapy. Cell Metab. 2016;23:63-76.

27. Mills EL, Kelly B, Logan A, Costa ASH, Varma M, Bryant CE, et al. Succinate dehydrogenase supports metabolic repurposing of mitochondria to drive inflammatory macrophages. Cell. 2016;167:457-70.

28. Tur J, Pereira-Lopes S, Vico T, Marin EA, Munoz JP, Hernandez-Alvarez M, et al. Mitofusin 2 in macrophages links mitochondrial ROS production, cytokine release, phagocytosis, autophagy, and bactericidal activity. Cell Rep. 2020;32:108079.

29. Koo SJ, Garg NJ. Metabolic programming of macrophage functions and pathogens control. Redox Biol. 2019;24:101198.

30. Coiffier B, Lepage E, Briere J, Herbrecht R, Tilly H, Bouabdallah $\mathrm{R}$, et al. CHOP chemotherapy plus rituximab compared with CHOP alone in elderly patients with diffuse large-B-cell lymphoma. N. Engl J Med. 2002;346:235-42.

31. Lokhorst HM, Plesner T, Laubach JP, Nahi H, Gimsing P, Hansson M, et al. Targeting CD38 with daratumumab monotherapy in multiple myeloma. N. Engl J Med. 2015;373:1207-19.

32. Beyar-Katz O, Magidey K, Reiner-Benaim A, Barak N, Avivi I, Cohen Y, et al. Proinflammatory macrophages promote multiple myeloma resistance to bortezomib therapy. Mol Cancer Res. 2019;17:2331-40.

33. Li YL, Shi ZH, Wang X, Gu KS, Zhai ZM. Tumor-associated macrophages predict prognosis in diffuse large B-cell lymphoma and correlation with peripheral absolute monocyte count. BMC Cancer. 2019;19:1049.

34. Kim D, Wang J, Willingham SB, Martin R, Wernig G, Weissman IL. Anti-CD47 antibodies promote phagocytosis and inhibit the growth of human myeloma cells. Leukemia. 2012;26:2538-45.

35. Ye Q, Song DG, Poussin M, Yamamoto T, Best A, Li C, et al. CD137 accurately identifies and enriches for naturally occurring tumor-reactive T cells in tumor. Clin Cancer Res. 2014;20:44-55.

36. Gordon SR, Maute RL, Dulken BW, Hutter G, George BM, McCracken MN, et al. PD-1 expression by tumour-associated macrophages inhibits phagocytosis and tumour immunity. Nature. 2017;545:495-9.

37. Murray PJ, Allen JE, Biswas SK, Fisher EA, Gilroy DW, Goerdt $\mathrm{S}$, et al. Macrophage activation and polarization: nomenclature and experimental guidelines. Immunity. 2014;41:14-20.

38. Palsson-McDermott EM, Curtis AM, Goel G, Lauterbach MA, Sheedy FJ, Gleeson LE, et al. Pyruvate kinase M2 regulates Hif1alpha activity and IL-1beta induction and is a critical determinant of the warburg effect in LPS-activated macrophages. Cell Metab. 2015;21:65-80.

39. Sabbagh L, Pulle G, Liu Y, Tsitsikov EN, Watts TH. ERKdependent Bim modulation downstream of the 4-1BB-TRAF1 signaling axis is a critical mediator of CD8 T cell survival in vivo. J Immunol. 2008;180:8093-101.

40. Chakraborty P, Chatterjee S, Ganguly A, Saha P, Adhikary A, Das $\mathrm{T}$, et al. Reprogramming of TAM toward proimmunogenic type through regulation of MAP kinases using a redox-active copper chelate. J Leukoc Biol. 2012;91:609-19.

41. Sharma P, Hu-Lieskovan S, Wargo JA, Ribas A. Primary, adaptive, and acquired resistance to cancer immunotherapy. Cell. 2017;168:707-23

42. Kienzle G, von Kempis J. CD137 (ILA/4-1BB), expressed by primary human monocytes, induces monocyte activation and apoptosis of B lymphocytes. Int Immunol. 2000;12:73-82.

43. Passlick B, Flieger D, Ziegler-Heitbrock HW. Identification and characterization of a novel monocyte subpopulation in human peripheral blood. Blood. 1989;74:2527-34.

44. Schmidl C, Renner K, Peter K, Eder R, Lassmann T, Balwierz PJ, et al. Transcription and enhancer profiling in human monocyte subsets. Blood. 2014;123:e90-99.

45. Martinez FO, Gordon S. The M1 and M2 paradigm of macrophage activation: time for reassessment. F1000Prime Rep. 2014;6:13.

46. Rodriguez-Prados JC, Traves PG, Cuenca J, Rico D, Aragones J, Martin-Sanz P, et al. Substrate fate in activated macrophages: a comparison between innate, classic, and alternative activation. J Immunol. 2010;185:605-14.

47. Jha AK, Huang SC, Sergushichev A, Lampropoulou V, Ivanova Y, Loginicheva E, et al. Network integration of parallel metabolic and transcriptional data reveals metabolic modules that regulate macrophage polarization. Immunity. 2015;42:419-30.

48. Lachmandas E, Boutens L, Ratter JM, Hijmans A, Hooiveld GJ, Joosten LA, et al. Microbial stimulation of different Tolllike receptor signalling pathways induces diverse metabolic programmes in human monocytes. Nat Microbiol. 2016;2: 16246.

49. Liu F, Liu W, Sanin DE, Jia G, Tian M, Wang H, et al. Heterogeneity of exhausted $\mathrm{T}$ cells in the tumor microenvironment is linked to patient survival following resection in hepatocellular carcinoma. Oncoimmunology. 2020;9:1746573.

50. Ochoa MC, Perez-Ruiz E, Minute L, Onate C, Perez G, Rodriguez I, et al. Daratumumab in combination with urelumab to potentiate anti-myeloma activity in lymphocyte-deficient mice reconstituted with human NK cells. Oncoimmunology. 2019;8:1599636.

51. Souza-Fonseca-Guimaraes F, Blake SJ, Makkouk A, Chester C, Kohrt HE, Smyth MJ. Anti-CD137 enhances anti-CD20 therapy of systemic B-cell lymphoma with altered immune homeostasis but negligible toxicity. Oncoimmunology. 2016;5:e1192740.

52. Tolcher AW, Sznol M, Hu-Lieskovan S, Papadopoulos KP, Patnaik A, Rasco DW, et al. Phase Ib study of utomilumab (PF05082566), a 4-1BB/CD137 agonist, in combination with pembrolizumab (MK-3475) in patients with advanced solid tumors. Clin Cancer Res. 2017;23:5349-57.

53. Eskiocak U, Guzman W, Wolf B, Cummings C, Milling L, Wu HJ, et al. Differentiated agonistic antibody targeting CD137 eradicates large tumors without hepatotoxicity. JCI Insight. 2020;5:5 